Georgia State University

ScholarWorks @ Georgia State University

$5-1-2014$

\title{
Impacts of the Affordable Care Act Dependent Coverage Provision on Health-Related Outcomes of Young Adults
}

\author{
Silvia Barbaresco \\ Georgia State University, sbarbaresco1@student.gsu.edu \\ Charles J. Courtemanche \\ Georgia State University, ccourtemanche@gsu.edu \\ Yanling Qi \\ Georgia State University, yqi3@gsu.edu
}

Follow this and additional works at: https://scholarworks.gsu.edu/uwrg_workingpapers

\section{Recommended Citation}

Barbaresco, Silvia; Courtemanche, Charles J.; and Qi, Yanling, "Impacts of the Affordable Care Act Dependent Coverage Provision on Health-Related Outcomes of Young Adults" (2014). UWRG Working Papers. 85.

https://scholarworks.gsu.edu/uwrg_workingpapers/85

This Article is brought to you for free and open access by the Usery Workplace Research Group at ScholarWorks @ Georgia State University. It has been accepted for inclusion in UWRG Working Papers by an authorized administrator of ScholarWorks @ Georgia State University. For more information, please contact scholarworks@gsu.edu. 


\section{W. J. Usery Workplace Research Group Paper Series}

Working Paper 2014-5-1

May 2014

\section{Impacts of the Affordable Care Act Dependent Coverage Provision on Health-Related Outcomes of Young Adults}

Silvia Barbaresco

Georgia State University

Charles J. Courtemanche Georgia State University \& NBER

Yanling Qi

Georgia State University 


\title{
Impacts of the Affordable Care Act Dependent Coverage Provision on Health-Related Outcomes of Young Adults
}

\author{
Silvia Barbaresco \\ Georgia State University \\ Email: sbarbaresco1@student.gsu.edu \\ Charles J. Courtemanche* \\ Georgia State University and National Bureau of Economic Research \\ Email: ccourtemanche@gsu.edu \\ Yanling Qi \\ Georgia State University \\ Email: yqi3@gsu.edu
}

May 14, 2014

\begin{abstract}
:
The first major insurance expansion of the Affordable Care Act - a provision requiring insurers to allow dependents to remain on parents' health insurance until turning 26 - took effect in September 2010. We estimate this mandate's impacts on numerous health-related outcomes using a difference-in-differences approach with 23-25 year olds as the treatment group and 27-29 year olds as the control group. For the full sample, the dependent coverage provision increased the probabilities of having insurance, a primary care doctor, and excellent self-assessed health, while decreasing unmet medical needs because of cost. However, we find no evidence of improvements in preventive care utilization or health behaviors. Subsample analyses reveal particularly striking gains for college graduates, including reduced obesity. Finally, we show that the mandate's impacts on 19-22 year olds were generally weaker than those on 23-25 year olds, although we observe a reduction in pregnancies for unmarried 19-22 year old women.
\end{abstract}

JEL Codes: I12, I13, I18

Keywords: Affordable Care Act, health care reform, young adults, dependent coverage, health insurance, health, self-assessed health, self-reported health, health behaviors, risky behaviors, preventive care, moral hazard

* Corresponding author. Department of Economics, Andrew Young School of Policy Studies, Georgia State University, Atlanta, GA 30303. Phone: (404)413-0082. Email: ccourtemanche@gsu.edu. 


\section{Introduction}

The Patient Protection and Affordable Care Act (ACA) of March 2010 aimed to achieve nearly universal coverage in the United States through a combination of mandates, subsidies, Medicaid expansions, and health insurance exchanges (Gruber, 2011). Although the majority of the ACA's provisions just took effect in 2014, one important component of the law - a dependent coverage provision - was implemented on September $23^{\text {rd }}$, 2010. This provision allows dependents to remain on a parent's private health insurance plan until the start of the first plan year after they turn 26 years old. Previously, private insurers often dropped non-student dependents at age 19 and student dependents at age 23 (Anderson et al., 2012 and 2014).

Many states already had some form of dependent coverage mandate before the ACA, but the state laws are typically weaker. Most state laws have an age threshold below 26 or require additional criteria, such as being a full-time student, living with one's parents, or not being married. Moreover, state laws do not apply to self-funded benefit programs, and more than half of private sector workers with employer-provided health insurance are in self-funded plans (Monheit et al., 2011). Perhaps because of these limitations, Monheit et al. (2011) and Levine et al. (2011) find that state dependent coverage mandates only lead to small increases in dependent coverage that are offset by a decline in young adults holding their own policies. In contrast, the ACA provision applies to all young adults under age 26 and all private plans. It therefore has the potential to dramatically affect young adults across the country, including in states with a preexisting dependent coverage provision.

The ACA dependent coverage expansion provides a unique opportunity to study the impacts of a health insurance intervention specific to young adults, the age group with the highest uninsured rate (Levine et al., 2011). Prior to the ACA, the uninsured rate was 29\% 
among individuals ages $18-24$ and $27 \%$ among those $25-34$, compared to $19 \%$ for $35-44$ year olds and 14\% for 45-64 year olds (DeNavas-Walt et al., 2010). Since any attempt to obtain universal coverage necessarily involves large coverage expansions among young adults, it is important to understand the effects of insurance on this group. It is unclear the extent to which results from other contexts - such as Medicaid, Medicare, or the Massachusetts health care reform of 2006 - are applicable. Young adults are generally healthier than the populations covered by these programs, and therefore may experience smaller gains from health insurance. Alternatively, young adults may be relatively poor and therefore respond strongly to reduced outof-pocket costs of medical care. ${ }^{1}$

Given the short amount of time since its implementation, researchers are only beginning to study the impacts of the ACA dependent coverage provision. Cantor et al. (2012) and Sommers and Kronick (2012) find that the mandate increased health insurance coverage for young adults across all racial groups and regardless of employment status. Sommers et al. (2013) show that the provision increased insurance coverage among young adults, while reducing delays in getting care and care foregone because of cost. Akosa Antwi et al. (2013) again find that the mandate increased insurance rates, but they also present evidence of labor market consequences such as young adults shifting from full-time to part-time jobs. These papers all share a common general research design: comparing changes in outcomes among the treated age range 19-25 to those of other young adults. Slusky (2013) questions the validity of this approach. He runs placebo tests using data from before the mandate and artificial "treatment" dates, finding that the same specification estimates significant "effects" more often than could be attributed to chance. Most recently, and concurrently with our paper, Akosa Antwi et al. (2014) show that the ACA

\footnotetext{
${ }^{1}$ Aside from age, the ACA dependent coverage mandate is also a unique coverage expansion in that it represents an expansion of private rather than public insurance, and that, since it only affects those whose parents have insurance, the treated population may be of higher socioeconomic status than that of other interventions.
} 
dependent coverage provision increased young adults' utilization of inpatient care for both emergency and non-emergency sources of admissions. They use a narrower age range of 23-25 for the treatment group and show that the models pass pre-treatment placebo tests.

We contribute to this growing literature by estimating the effects of the ACA dependent coverage provision on a much broader range of health-related outcomes than those previously examined. In contrast to prior studies' focus on insurance status, labor market outcomes, and hospitalizations, we investigate 18 outcomes related to health care access, utilization of preventive care, risky health behaviors, and self-assessed health. The health care access outcomes include having insurance, a primary care doctor, and any foregone care because of cost. Our preventive care measures are dummies for recent flu vaccinations, well-patient checkups, and pap tests. The health behavior outcomes reflect smoking, drinking, body mass index, exercise, and pregnancy. The self-assessed health variables relate to overall, mental, and physical health as well as health-related limitations.

We estimate difference-in-differences models with the treatment group consisting of individuals ages 23-25, slightly below the dependent coverage provision's age cutoff, and the control group consisting of those slightly above the cutoff at ages $27-29$. Our data come from the Behavioral Risk Factor Surveillance System (BRFSS). The results from the full sample suggest that the ACA dependent coverage provision improved health care access for young adults, had little effect on preventive care use or risky health behaviors, and improved self-assessed health but only at the high end of the distribution. Specifically, we document increases in the probabilities of having health insurance coverage, a primary care doctor, and excellent selfassessed health, decreases in medical care foregone because of cost and the probability of obtaining a flu vaccination, and no clear changes in the other outcomes. We argue for a causal 
interpretation of these results by performing placebo tests that check for "effects" of artificial interventions both in the pre-treatment period (akin to Slusky, 2013) and among those slightly too old to be affected by the actual ACA mandate.

We also evaluate heterogeneity in the effects of the mandate by stratifying the sample by prior state dependent coverage mandate status, sex, race, and education. The subsample analyses reveal greatest improvements in outcomes for men and college graduates. The benefits for college graduates are particularly striking. Not only are the impacts on probabilities of having a primary care doctor, reporting excellent health, and foregone medical care especially large, but the reduction in flu vaccinations becomes statistically insignificant and new favorable effects emerge: increases in the probability of having a well-patient checkup and reporting very good or excellent health, as well as a reduction in obesity.

We close by testing for effects of the dependent coverage provision on younger young adults ages 19-22, using 18 and 27 year olds as the control group. The estimated effects on 19-22 year olds are generally weaker than those on 23-25 year olds, but we do observe one interesting new result: a reduction in pregnancies for unmarried women.

\section{Health Insurance and Health-Related Outcomes}

The most obvious theoretical implication of health insurance is that by lowering the effective price of health care, health insurance should increase its utilization (the "access effect", according to Dafny and Gruber, 2005). However, insurance might also lead to substitution across different types of services. For instance, if insurance increases preventive services such as doctor checkup visits and screenings, this in turn might prevent hospital visits (the "efficiency effect").

While it might be natural to expect that improved access to health care would improve health, this is not automatically the case. According to the standard health capital model (e.g. 
Grossman, 1972), diminishing marginal returns suggest that health care can only improve health up to a certain level; any care beyond that is wasteful ("flat of the curve" care). Whether the additional consumption of medical care induced by insurance generates substantial gains in health therefore depends on the initial level of health capital. Since the uninsured can often obtain essential needs by paying directly or receiving charity care, it is not clear that these individuals automatically have low baseline levels of health. Moreover, the marginal returns to health care differ for different conditions. Risky health behaviors such as smoking, excessive drinking, and overeating might be particularly difficult to improve through health care, as they require lifestyle changes on the part of the patient. Medical professionals can provide accountability, information, strategies, and sometimes drugs that can make behavioral changes easier, but these conditions are still harder to treat than, for instance, asthma.

Another relevant issue when evaluating the impact of health insurance on health is that obtaining insurance could induce individuals to take more health risks, since the provision of health insurance decreases the financial losses associated with sickness. This concept is known as ex ante moral hazard (Ehrlick and Becker, 1972). Theoretically, ex ante moral hazard could both increase risky behaviors and reduce investments in preventive care.

Finally, exogenous provision of health insurance could lead to income effects for individuals who used to purchase their own insurance policy but now are able to receive free or subsidized coverage, or for the newly-insured if their out-of-pocket medical expenses drop. The available causally-interpretable evidence from natural experiments suggests that additional income increases health care utilization (Acemoglu et al., 2013), either increases BMI or has no effect (Lindahl, 2005; Schmeiser, 2009; Cawley et al., 2010), increases smoking along the intensive but not extensive margin (Apouey and Clark, 2014), and increases drinking (Apouey 
and Clark, 2014). The income effect may therefore improve health via medical care but worsen health via risky behaviors. Accordingly, evidence of income's causal effect on overall health is mixed, with Lindahl (2005) and Frijters et al. (2005) finding that it improves self-assessed health, Apouey and Clark (2014) finding that it improves mental health but not overall health, and Snyder and Evans (2006) showing that it raises mortality risk among seniors.

In sum, the effects of insurance on preventive health care utilization, risky health behaviors, and overall health status are theoretically ambiguous. Insurance may improve these outcomes through direct price effects, worsen them through ex ante moral hazard, or affect them in either direction through income effects. The net effects could differ for different outcomes. For instance, one might expect direct price effects to dominate for primary care utilization but moral hazard to dominate for risky behaviors. Empirical analysis is necessary to resolve this ambiguity.

Quasi-experimental evidence generally confirms the prediction that insurance increases health care utilization for U.S. adults. Manning et al. (1987) analyzed the randomized RAND Health insurance experiment, finding that lower copayments increased doctor visits. Medicaid and Medicare expansions have been shown to increase utilization of primary and hospital care (Currie and Gruber, 1996a; Finkelstein et al., 2012; Taubman et al., 2014; Lichtenberg, 2002; Card et al., 2008). Other evidence suggests that the Massachusetts universal coverage initiative of 2006 increased preventive services while reducing emergency room utilization, avoidable hospitalizations, and medical needs unmet because of cost (Miller, 2011; Kolstad and Kowalski, 2012; Miller, 2012; Van der Wees et al., 2013). More directly relevant to our study population, Anderson et al. (2012 and 2014) exploit the sharp drops in coverage on parents' insurance at ages 19 and 23 to show that losing coverage reduced young adults' emergency room and hospital 
visits. Finally, as mentioned previously, Akosa Antwi et al. (2014) show that the ACA dependent coverage provision increased both emergency and non-emergency admissions to hospitals.

The evidence of health insurance's effect on health is less clear. The RAND experiment only found that better insurance coverage improved cholesterol, physical health, or mental health for certain subgroups (Brook et al., 1983). Medicaid expansions have been estimated to increase self-reported overall, physical, and mental health and reduce mortality, but have no statistically detectable effects on laboratory-measured health outcomes (Currie and Gruber, 1996b; Finkelstein et al., 2012; Sommers et al., 2012; Baicker et al., 2013). Card et al. (2008) find a reduction in the mortality rate among recently hospitalized Medicare recipients, but Finkelstein and McKnight (2008) find no significant effect of Medicare on the mortality rate of seniors in general. Finally, evidence suggests that the Massachusetts reform improved self-assessed overall, physical and mental health, while decreasing functional limitations, joint disorders, and mortality (Van der Wees et al., 2013; Courtemanche and Zapata, 2014; Sommers et al., 2014).

Evidence on the causal effects of health insurance on risky health behaviors is also mixed. Brook et al. (1983) find no evidence that insurance affected smoking or body weight in the RAND experiment. Dave and Kaestner (2009) report that Medicare decreased physical activity while increasing smoking and drinking, but none of these effects were statistically significant. Finkelstein et al. (2012) do not find any significant impacts of Medicaid on smoking or BMI. Courtemanche and Zapata (2014) find no evidence that the Massachusetts reform affected smoking or physical activity, and actually find that it reduced body mass index.

In sum, there is little prior evidence on the effects of health insurance on young adults' access to care, preventive care utilization, risky health behaviors, or health. Anderson et al. (2012 and 2014) and Akosa Antwi et al.'s (2014) studies on young adults focus only on hospital care. 
Given the theoretical ambiguities and variation in empirical findings discussed above, we cannot assume prior results from other contexts such as Medicaid and Medicare generalize. For instance, young adults' relatively high baseline levels of health might lead them to have relatively inelastic demand for health care or a low marginal effect of health care on health. On the other hand, young adults' demand for health care could be relatively elastic given their generally low income and wealth levels. Moreover, one might expect young adults to be the most susceptible to ex ante moral hazard since this is often the life stage in which opportunities to engage in particular risky behaviors (e.g. binge drinking) are introduced.

\section{Data}

Our main data source is the BRFSS, a telephone survey conducted by state health departments in conjunction with the U.S. Centers for Disease Control and Prevention to collect information on health and health behaviors. The survey is conducted monthly through a random digit dialing method that selects a representative sample of respondents from the noninstitutionalized population of adults at least 18 years old. The BRFSS provides several advantages for our analyses. First, it contains a wide range of appropriate outcome variables. Second, it includes demographic characteristics as well as state, month, and year identifiers that allow us to construct the treatment variable and jointly control for many different factors. Next, it contains a much larger number of observations than other datasets with the necessary variables. Finally, the BRFSS includes a number of pre-treatment waves that allow for detailed testing of differential trends in the outcomes between treatment and control groups.

Our primary analysis sample consists of the 2008-2012 waves, which include the year the ACA dependent coverage mandate took effect as well as two years on both sides. We exclude the years before 2008 in order to limit our sample to years of relatively poor economic 
performance. This reduces the possibility of confounding from differential impacts of macroeconomic shocks on the health-related outcomes of different age groups. However, robustness checks and placebo tests will utilize data as far back as 2001. We do not use any waves before 2001 because the BRFSS made major changes to the survey in that year. Many of the questions used to construct our outcome variables are either not available in earlier years or differ in non-trivial ways.

Most of our analyses use ages 23-25 as the treatment group and ages 27-29 as the control group. Following most of the prior literature, 26 year olds are excluded because their treatment status is ambiguous: they may still be covered by the ACA mandate depending on their birthdate and the start date of their parents' insurance plan year (Akosa Antwi et al., 2013). Several prior papers in the literature use 19-25 as the treatment group, but we prefer 23-25 for two reasons. ${ }^{2}$ First, prior to the ACA, insurers most commonly dropped non-student dependents from parents' plans at age 19, but most commonly dropped student dependents at age 23. Excluding 19-22 year olds therefore results in a "cleaner" treatment group, i.e. a higher proportion of the treatment group actually being affected by the treatment. Accordingly, Akosa Antwi et al. (2014) show that the ACA dependent coverage provision's impact on having insurance was more than twice as large for 23-25 year olds as for 19-22 year olds. Second, Slusky (2013) shows that the models from prior papers with ages 19-25 as the treatment group lead to poor placebo test results for insurance and labor market outcomes. He suggests narrowing the age bandwidth as a potential solution. Indeed, we will show that wider age ranges lead to problematic placebo test results for our outcomes as well, and that our narrower age range performs better.

\footnotetext{
${ }^{2}$ Studies using 19-25 year olds as the treatment group include Cantor et al. (2012), Sommers et al. (2012, 2013), and Akosa Antwi et al. (2013). Cantor et al. (2012) use 27-30 year olds as the control group, while Sommers et al. (2012, 2013) use 26-34 year olds and Akosa Antwi et al. (2013) use 16-18 and 27-29 year olds.
} 
We utilize eighteen different health-related dependent variables. The first three relate to health care access: dummy variables reflecting whether the respondent has any health insurance, has a primary care physician, and had any medical care needed but not obtained because of cost in the previous year. ${ }^{3}$ The next three outcomes - dummies for having a flu vaccination (shot or spray), a well-patient doctor check-up visit (i.e. physical), and a pap test (for women) in the previous year - reflect preventive care utilization. Other preventive care variables typically studied in the literature (e.g. mammograms and prostate exams) are not relevant for our study population of young adults. The next category of variables relates to risky health behaviors: a dummy for whether the individual currently smokes, number of alcoholic drinks in the past 30 days, a dummy for being a risky drinker (more than 30 drinks total or at least one occasion with four or more drinks for women, more than 60 drinks total or at least one occasion with five or more drinks for men), ${ }^{4}$ body mass index (BMI=weight in $\mathrm{kg} /$ height in $\left.\mathrm{m}^{2}\right),{ }^{5}$ a dummy for obese (BMI $\geq 30$ ), a dummy for whether an unmarried female respondent is pregnant (the only proxy for risky sexual activity available in the BRFSS), and a dummy for obtaining any recreational exercise in the past 30 days. ${ }^{6}$ Finally, we include several variables related to self-assessed health status: a dummy for whether overall health is very good or excellent, a dummy for whether overall health is excellent, and days of the last 30 not in good mental health, not in good physical health, and with health-related functional limitations. Although self-assessed health is subjective,

\footnotetext{
${ }^{3}$ The BRFSS does not include more detailed questions on health insurance, such as the source of coverage.

${ }^{4}$ The dummy for risky drinker is created to come as close as the BRFSS data will allow to the National Institute on Alcohol Abuse and Alcoholism's definition of at-risk drinking: more than 7 drinks per week total or at least one occasion with three or more drinks for women, and more than 14 drinks per week total or at least one occasion with four or more drinks for men. See http://pubs.niaaa.nih.gov/publications/womensfact/womensfact.htm.

${ }^{5}$ Body mass index is based on self-reported height and weight, which are prone to measurement error (Cawley, 2004). Researchers have repeatedly found that this measurement error does not affect the signs and significance of regression estimates with BMI as a dependent variable, though it may slightly attenuate the magnitude of the estimates (e.g. Lakdawalla et al., 2002; Courtemanche et al., 2014; Courtemanche et al., forthcoming).

${ }^{6}$ Unfortunately, the more detailed BRFSS questions on physical activity are only available in odd numbered survey years and changed dramatically in 2011, so they are not useful for our analyses.
} 
research has repeatedly found it to be correlated with objective measures of health such as mortality (e.g. Idler and Benyamini, 1997; DeSalvo et al., 2006; Phillips, Der, and Carroll, 2010). Self-assessed health also has the advantage of being a global measure of health that captures the full range of possible diseases and limitations (Idler and Benyamini, 1997). ${ }^{7}$

We also utilize a wide array of control variables. These include dummy variables for each year of age, gender, race/ethnicity, marital status, education, household income category, number of children in the household, whether the respondent reports her primary occupation as student, and whether the respondent is unemployed. Additionally, we control for monthly state unemployment rate, obtained from the Bureau of Labor Statistics. As mentioned previously, we are concerned about different impacts of the recession on different age groups, so controlling for several variables related to economic conditions at both the individual and aggregate levels could potentially be important. We also control for whether the respondent's state had any dependent coverage mandate covering her age*marital status*student status group in the survey year based on information from the National Conference of State Legislatures (2010). ${ }^{8}$

Finally, we include a dummy for whether the respondent is part of a "cell phone only" component of the sample, added in 2011 (this variable is 0 for all respondents before 2011). The fact that individuals who only used cell phones were not explicitly included in the sample until 2011 raises the question of whether our sample makeup meaningfully changed at about the same time the post-treatment period began. To address this issue, we not only control for "cell phone only" users but also utilize the BRFSS sampling weights in all analyses. We found that these

\footnotetext{
${ }^{7}$ Moreover, other commonly-used measures of health are not practical in our context. Mortality rates are likely too low among young adults to estimate effects of coverage expansions with meaningful precision, while measures of avoidable hospitalizations confound insurance's impact on health with the reduction in effective prices.

${ }^{8}$ Note that not everyone coded as a 1 for state mandate is actually "treated" by such a mandate. Additional qualifiers beyond age, student status, and marital status exist in some states, while young adults whose parents' employers self-insure are also not covered by state mandates.
} 
weights eliminate any sharp changes in sample demographic characteristics in 2011. Additionally, this issue would only bias our regression estimates if the relationship between the outcomes of landline and cell phone users is different among 23-25 year olds than among 27-29 year olds, and in a way that is not captured by the controls. It is not obvious why this would be the case. Accordingly, we have verified (results available upon request) that dropping individuals who only use cell phones from our sample has very little effect on the coefficient estimates, though it does generally increase the standard errors due to the reduced sample size.

After excluding observations with missing data for any of the control variables, Table 1 reports the sample sizes for the regressions for each dependent variable, along with the numbers of individuals in the treatment and control groups. The sample sizes differ slightly across dependent variables for two reasons. First, each health-related variable is missing for a different number of respondents. Second, the health-related variables have different "reflection periods;" some apply to the present (e.g. current smoker), while others refer to a 30-day period (e.g. number of alcoholic drinks in the past 30 days) and others to a one-year period (e.g. well-patient doctor visit in the past year). We are concerned that short-run estimates would be misleading for variables with a long reflection period. ${ }^{9}$ We therefore drop respondents who are surveyed during this period of ambiguity; e.g. for well-patient doctor visits we drop observations from October 2010 through September 2011, while for drinks in the past 30 days we drop only October 2010.

Table 2 lists the control variables and compares the pre-treatment (January 2008 through September 2010) summary statistics of the treatment and control groups. Individuals in the treatment group are less likely to be married, have a college degree, earn a high income, and have children in the household, and they are more likely to be students or employed.

\footnotetext{
${ }^{9}$ For example, suppose a respondent is surveyed in November 2010, the second month of the post-implementation period. The respondent would be classified as post-treatment, but her answer about well-patient doctor visits in the past year would reflect only two months of the post-treatment period and ten months of the pre-treatment period.
} 
Table 3 reports the pre- and post-treatment sample means of the outcome variables for the treatment and control groups, and calculates the simple difference-in-difference of means. Prior to the ACA dependent coverage provision, the uninsured rate was higher for young adults in the treatment group than those in the control group. The treatment group had lower rates of health care utilization and health care access than the control group; slightly higher drinking and unmarried pregnancy rates but healthier levels of risky drinking, BMI, obesity, and exercise; and broadly similar levels of smoking and self-assessed health. Comparing changes in the post- and pre-treatment means for the treatment and control groups, the difference-in-differences are positive and significant for any insurance, primary care doctor, and excellent health, negative and significant for care needed but not obtained because of cost, and insignificant for the other outcomes - including all those in the preventive care and health behavior categories.

Simple difference-in-differences estimates account for fixed differences in unobservable characteristics between the treatment and control group, but are still susceptible to bias from time-varying observables and unobservables. Figures 1-3 show that at a first glance the pre-ACA trends for the treatment and control groups appear generally similar for most outcomes, providing preliminary evidence that changes over time in observables and unobservables may not be substantially different for 23-25 year olds and 27-29 year olds. We next turn to regression analyses that adjust for changes in observables. Later, we will also conduct more formal tests of the assumption of common trends in unobservables.

\section{Average Effects of the ACA Dependent Coverage Mandate}

We estimate the effects of the ACA dependent coverage provision on the 18 healthrelated outcomes using difference-in-differences regressions. We prefer reduced-form models to instrumental variables models using the mandate as an instrument for having insurance coverage 
because there are several other mechanisms through which the mandate could affect healthrelated outcomes besides the extensive margin of health insurance coverage. Other possible mechanisms include the intensive margin of coverage (switching from high deductible catastrophic coverage to more comprehensive coverage), income effects, and peer effects.

Our baseline regression is of the form

$$
Y_{i g s t}=\beta_{0}+\beta_{1}\left(\text { Treat }_{g} * \text { Post }_{t}\right)+\beta_{2} \boldsymbol{X}_{\text {igst }}^{\prime}+\alpha_{g}+\varphi_{t}+\sigma_{s}+\varepsilon_{i g s t}
$$

where $Y_{\text {igst }}$ is the health-related outcome for individual $i$ of age $g$ living in state $s$ in time $t$, expressed in a month/year combination. ${ }^{10}$ Treat $_{g}$ is a dummy variable for whether age $g$ is in the treated age range 23-25 as opposed to the control age range 27-29. Post $t_{t}$ indicates whether period $t$ is after the implementation of the provision (October 2010 or later). ${ }^{11} \beta_{1}$ is the difference-in-differences coefficient and it captures the difference between the effect of the mandate on the treatment group relative to the control group. $\boldsymbol{X}_{\boldsymbol{i g s t}}^{\prime}$ is a vector of the aforementioned control variables for sex, race, marital status, education, income, children, cell phone survey, student status, individual and state unemployment, and state dependent coverage mandate. We also include fixed effects for each year of age, month/year of time (e.g. January of 2008), and state, denoted by $\alpha_{g}, \varphi_{t}$, and $\sigma_{s}$, respectively. $\varepsilon_{\text {igst }}$ is the error term. ${ }^{12}$ We report heteroskedasticity-robust standard errors clustered at the level of treatment: the age/time interaction. ${ }^{13}$

\footnotetext{
${ }^{10}$ Even though most of our outcomes are binary or non-negative count, we estimate linear models because they typically give reliable estimates of average effects (Angrist and Pischke, 2008). In unreported regressions (available upon request), we verify that the average treatment effects are very similar using probit regressions for the binary outcomes and negative binomial regressions for the count outcomes.

${ }^{11}$ Treat $_{g}$ and Post $_{t}$ are not separately included because the age and time fixed effects subsume Treat $g$ and Post $_{t}$.

${ }^{12}$ In unreported regressions (available upon request) we have verified the results remain virtually identical if we replace the state fixed effects with fixed effects for each state-by-year combination.

${ }^{13}$ Standard errors are generally similar if we cluster by only age. We prefer, however, to cluster by age*time in our reported estimates because clustering by only age results in too few clusters (11 in the full sample, 6 in the restricted sample) to be reliable (Angrist and Pischke, Chapter 8).
} 
The key identifying assumption in a difference-in-differences model is common counterfactual trends between the treatment and control groups; i.e. in the absence of the intervention the treatment and control groups would have experienced the same changes in outcomes. Slusky (2013) argues that this assumption is problematic when studying the impact of the ACA dependent coverage provision on labor market-related outcomes (e.g. sources of health insurance coverage, employment status, and work hours) since cyclical fluctuations in the economy have different effects on different age groups. In our view, the difference-in-differences identifying assumption seems somewhat less troublesome for health outcomes than labor market outcomes, since health outcomes are less directly tied to cyclical fluctuations in the economy. ${ }^{14}$ Moreover, using narrow age bandwidths of 23-25 and 27-29 should substantially mitigate any differential shocks that may exist.

We also estimate several variations of (1) as robustness checks. First, we run regressions including only the demographic controls (the sex, age, race, children, and marital status dummies) and fixed effects, excluding the economic controls since they may be endogenous and the resulting bias could potentially spill over into the coefficient estimate of interest. Next, in order to verify that the results are not driven by our chosen length of the pre-treatment period, we consider two alternatives: starting the sample in 2005 and 2001. Finally, we run regressions dropping March 2010 through December 2010, as these months are somewhat ambiguous with respect to their treatment status. We drop March-September because the ACA was passed in March, so some insurance plans may have complied preemptively prior to the dependent coverage provision’s official implementation in September. We drop October-December because,

\footnotetext{
${ }^{14}$ Although research shows that recessions are associated with improvements in health and health behaviors (e.g. Ruhm, 2000, 2002, and 2005), we are unaware of any evidence that economic cycles differentially impact different age groups of young adults. Moreover, recent research suggests that the countercyclical nature of health observed in prior recessions was not present during our sample period (Ruhm, 2013 and Tekin et al., 2013).
} 
even though the mandate was implemented in September, insurers did not have to comply until the start of the next plan year, which is often January. ${ }^{15}$

Table 4 presents the results for the baseline model and robustness checks. In addition to reporting estimated treatment effects and standard errors, for the baseline regressions we also report (in brackets) the treatment effect expressed in standard deviations of the dependent variable to provide some comparability of effect sizes across the different outcomes.

The results suggest sizeable improvements in health care access. We estimate that the ACA dependent coverage provision statistically significantly increased the insurance coverage rate of 23-25 year olds by 5.6-6.7 percentage points. This is somewhat larger than the around 3-5 percentage point increase estimated by previous studies that use the broader treated age range of 19-25 (Cantor et al., 2012; Sommers and Kronick, 2012; Akosa Antwi et al., 2013; Sommers et al., 2013). ${ }^{16}$ Additionally, the mandate decreased the probability of having any care needed but foregone because of cost by 2.2-2.8 percentage points and increased the probability of having a primary care doctor by 1.8-3.9 percentage points.

However, we do not find any evidence of increased preventive care utilization. We estimate a statistically significant 2.1-2.7 percentage point decrease in the probability of having a flu vaccination, which may be due to young adults with insurance coverage being less afraid of facing financial problems caused by further health treatments - potentially hospitalizations - if they get the flu. This is consistent with ex ante moral hazard. We find no statistically significant effect of the mandate on well-patient checkups or pap tests for women.

\footnotetext{
${ }^{15}$ Akosa Antwi et al. (2013) include two treatment variables to separately model the effects of the mandate during the implementation period and after full implementation. We have considered this specification in unreported regressions and the estimated post-implementation effects remain very similar.

${ }^{16}$ This discrepancy is consistent with Akosa Antwi et al.'s (2014) finding that the mandate's impact on the probability of having any coverage was around twice as large for 23-25 year olds than 19-22 year olds (4 compared to 2 percentage points). Alternatively, estimates using the treated age range 19-25 could be biased downward given the problems documented in our placebo tests and those of Slusky (2013).
} 
We also find no clear evidence that the dependent coverage provision influenced risky health behaviors. Across 7 dependent variables with 5 specifications each, we do not observe a single statistically significant estimate. This is somewhat remarkable, since out of 35 estimates we would expect at least one to be significant simply by chance. With that said, in every specification the mandate is associated with increases in drinks per month and risky drinking and decreases in BMI and obesity, even though the estimates are never statistically significant. It is theoretically conceivable that insurance coverage could increase drinking but reduce weight, as health care access may be more helpful for losing weight than reducing drinking. Gains in information and accountability may both be greater for weight control than drinking: dieting strategies can be complicated and benefit greatly from professional advice, and accountability is greater for weight since patients are weighed at each visit. The direct price effect could therefore dominate for BMI, while the ex ante moral hazard effect could dominate for drinking. Income effects may play a role as well, especially for alcohol consumption given the aforementioned evidence of a positive causal effect of income on drinking (Apouey and Clark, 2014).

Turning to the self-assessed health outcomes, the mandate increased the probability of young adults reporting excellent overall health by 2.1-2.4 percentage points, but the effect on reporting very good or excellent health was smaller and only statistically significant in two regressions. Together, these results suggest that most of the mandate's effect on health occurs by transitioning young adults from very good to excellent health, which is perhaps not surprising given the high baseline health level of this age group. Possibly for this reason, we do not find any evidence of effects on the variables representing more severe health problems: days not in good mental health, not in good physical health, and with health-related functional limitations. 
Finally, we provide a brief discussion of the relative magnitudes of the effects on different outcomes by comparing the treatment effects expressed in standard deviations of the dependent variables. Not surprisingly, the largest effect of 0.132 standard deviations is on the probability of having any health insurance coverage. The next largest effects are on personal doctor visits (0.064 standard deviations), flu vaccinations (-0.062 standard deviations), care prevented because of cost (-0.058 standard deviations), and excellent health (0.051 standard deviations). Although not significant, the mandate's effect on drinks per month is the next largest (0.037 standard deviations). The other statistically insignificant effects are generally quite small, ranging from 0.005 to 0.025 standard deviations.

\section{Placebo Tests}

We next provide a series of placebo tests to evaluate whether the previous results can credibly be interpreted as causal effects of the ACA dependent coverage provision. We first follow Slusky's (2013) approach and estimate variants of equation (1) that test for "effects” of artificially-timed "treatments" during pre-treatment years. We estimate models for five different five-year windows of pre-treatment data (to match the five years used in our main 2008-2012 analyses): 2005-2009, 2004-2008, 2003-2007, 2002-2006, and 2001-2005. Since the first month after the implementation of the actual dependent coverage mandate was the $34^{\text {th }}$ month (October 2010) of our 2008-2012 sample, in each placebo test sample we date the implementation of the artificial intervention to the $34^{\text {th }}$ month (e.g. October 2007 for the 2005-2009 sample). We estimate (1) for each of the 18 dependent variables in each of the five placebo test samples.

Placebo tests using pre-treatment data will detect differential underlying trends between treatment and control groups, but they are not able to detect potential confounding from unique shocks to treatment and control groups that do not emerge until the time of treatment. For 
instance, if different age groups of young adults followed similar trends in health until the Great Recession, at which point some groups' health changed relative to others, the model would pass pre-treatment placebo tests but still produce invalid estimated effects of the mandate. We therefore consider an additional placebo test that utilizes the actual date of the mandate's implementation. Specifically, we estimate model (1) with 2008-2012 data, but define artificial treatment and control groups as being the youngest age ranges possible that do not include the actual treated ages. Whereas our main sample classifies those $23-25$ as the treatment group and 27-29 as the control group, the sample for this placebo test therefore uses those $27-29$ as the treatment group and 31-33 as the control group. We drop age 30 to parallel our dropping of age 26 in the main sample. This test evaluates whether different groups of young adults experienced different shocks at around the time of the ACA.

Table 5 reports the coefficient estimates of interest from these placebo tests. We run six tests for each of the 18 dependent variables, though in three cases tests are not possible because the dependent variable is not available in some of the early years. This leaves a total of 105 regressions. Given the large number of estimates, we would expect some significant results even for valid models. Specifically, approximately 1 estimate should be significant at the $1 \%$ level, 4 5 at the $5 \%$ level, and 9-10 at the $10 \%$ level. We obtain numbers in the vicinity of these. 4 estimated "treatment effects" (3.8\%) are significant at the 1\% level, 7 (6.7\%) at the 5\% level, and $10(9.5 \%)$ at the $10 \%$ level. Moreover, we do not observe any clear evidence of sustained differential pre-treatment trends between the treatment and control groups, as there are no dependent variables for which the placebo tests consistently produce either significant positive or significant negative coefficient estimates. 
Also, it is interesting to note that most of the placebo test failures are concentrated among two outcomes: primary care doctor (2 out of 6 ) and smoker (3 out of 6). Indeed, excluding these variables the placebo tests only reject the null hypothesis $0.95 \%$ of the time at the $1 \%$ level, $2.9 \%$ at the $5 \%$ level, and $4.8 \%$ at the $10 \%$ level. Therefore, a more nuanced interpretation of our placebo test results would be that the model performs very well for most outcomes but somewhat problematically for two. We therefore next conduct additional robustness checks of the main specification for the two problematic outcomes. Specifically, we narrow the age bandwidth further, thereby presumably reducing the differences in unobservable characteristics between the treatment and control groups. The first additional robustness check uses only ages $24-25$ as the treatment group and ages $27-28$ as the control group, while the second check uses just ages 25 and 27. It should be noted that we would not necessarily expect the robustness check results to remain identical to those from the main specification even if both models are valid. The causal effects of the dependent coverage provision may be genuinely different for 23, 24, and 25 year olds. Indeed, this is the reason we do not perform similar robustness checks for all the outcomes. Table 6 reports the results from these additional robustness checks for primary care doctor and smoker. The conclusions reached are the same as those from the main specification.

Finally, in the interest of contributing to the broader debate in the literature about the appropriateness of different age bandwidths when using difference-in-differences models to estimate the effects of the ACA dependent coverage provision, we also run the same set of placebo tests for numerous wider age ranges than our preferred specification: 1) treatment group 22-25 and control group 27-30, 2) treatment group 21-25 and control group 27-31, 3) treatment group 20-25 and control group 27-32, 4) treatment group 19-25 and control group 27-33, and 5) treatment group 19-25 and control group 18 plus 27-29. Case 4 is the most similar specification 
to the majority of studies in the literature (Cantor et al., 2012; Sommers and Kronick, 2012; Sommers et al., 2013), while case 5 is most similar to Akosa Antwi et al. (2013). For the placebo tests with individuals too old to be affected by the mandate, we again use the closest parallel construction that excludes treated ages. For instance, when the treatment group is 19-25 and the control group is 27-33, the artificial treatment and control groups are ages 27-33 and 35-41, respectively. Table 7 summarizes the results from these placebo tests with wider age bandwidths; the full results are available upon request. Our preferred treatment and control groups - in bold perform noticeably better than those using wider age ranges. The number of null hypothesis rejections at the $10 \%$ level is the lowest, while the number of outcomes with no placebo test failures and the number with only one failure are the highest.

\section{Heterogeneity}

Having established our baseline results and assessed the validity of our model, we next turn to an examination of heterogeneity in the treatment effects. Tables 8 and 9 report results for subsamples defined based on whether the respondent's state had any pre-ACA dependent coverage provision as well as the respondent's sex, race, and education. The mandate should affect young adults in all states regardless of the given limitations of the state laws discussed in Section I, but we might expect stronger effects in states without any pre-ACA mandates. However, this may not necessarily be the case: Monheit et al. (2011) and Levine et al. (2011) find minimal effects of state dependent coverage provisions on uninsured rates, while Akosa Antwi et al. (2013) did not find meaningfully different effects of the ACA dependent coverage provision on coverage rates by pre-ACA state law status. The ACA mandate may have differential impacts by sex or race if demographic groups differ in their pre-ACA insurance coverage rates or propensity to alter health care utilization and health behaviors in responses to 
obtaining coverage. The nature of heterogeneity by education is unclear. Young adults of high socioeconomic status may be more likely to both have their own employer-provided health insurance and to have parents with employer-provided coverage. Responses to obtaining coverage may also differ by education, as Grossman (1972) posits that more educated individuals are more efficient producers of health given the same amount of inputs.

The first two columns of Table 8 show the results stratified by pre-ACA state law status. Sizeable coverage expansions are evident in both subsamples, though the increase is somewhat larger for individuals in states without any prior mandate (8.9 percentage points compared to 5.1). The patterns for the other outcomes are mixed, with the effect on overall self-assessed health being larger in states with no pre-ACA dependent coverage provision but the impacts on having a primary care doctor, care foregone because of cost, and flu shots being smaller in these states. It is not necessarily contradictory that the effects on some outcomes are stronger in the opposite subsample of the one with the larger increase in probability of having health insurance. Responses to obtaining insurance coverage could differ across subsamples, while changes in the intensive margin of coverage (source and generosity of coverage) could also influence outcomes and we are unable to measure such changes in our data.

The last two columns of Table 8 report the results separately for women and men. The favorable effects on the probabilities of having health insurance coverage, a primary care doctor, foregone care because of cost, and excellent overall health are all stronger for men, while the adverse effect on flu vaccinations is stronger for women. Interestingly, women do not experience a statistically significant improvement in any outcomes besides health insurance coverage. Instead, they reduce flu vaccinations and slightly increase smoking and days of health-related limitations. In contrast, men do not experience a single statistically significant adverse effect (the 
reduction in flu vaccinations is insignificant). These patterns could potentially be explained by greater ex ante moral hazard among women or greater price sensitivity in preventive health care utilization among men, although future research would be necessary to test these hypotheses more directly.

Turning to Table 9, the first two columns split the sample into non-Hispanic whites and those of another race/ethnicity. ${ }^{17}$ The impacts of the ACA dependent coverage mandate on insurance coverage are virtually identical for the two groups, and many of the other results are also similar. However, an important difference is that significant improvements in care foregone because of cost and excellent self-reported health are only observed for whites. In fact, the only significant effect for non-whites in the self-assessed health category is a small and marginally significant worsening of physical health. On the other hand, the increase in probability of having a primary care doctor is almost twice as large for non-whites as whites. One explanation that would fit with this pattern of results is if non-white young adults were more likely to utilize safety net care prior to obtaining insurance coverage; in this case, they would not have a primary care doctor but still have their critical health care needs met. Again, however, directly testing this hypothesis is beyond the scope of this paper.

Finally, the last two columns of Table 9 report the results stratifying by college degree attainment. $^{18}$ The increase in the probability of having any coverage is slightly larger for those without a college degree, but the rest of the results are substantially more favorable for college graduates. College graduates experience substantially larger improvements in the probabilities of having a primary care doctor, care foregone because of cost, and excellent overall self-assessed

\footnotetext{
${ }^{17}$ We attempted further stratification within the non-white category but the estimates became too imprecise to be useful.

${ }^{18}$ Again, further stratification led to estimates that were too imprecise to be useful. Note that we do not include a separate category for current students because our sample only includes those 23 and older, so the proportion of our respondents reporting "student" as their primary occupation is low.
} 
health than those estimated earlier for the full sample, while the reduction in flu shots becomes statistically insignificant. Moreover, new favorable statistically significant effects emerge: increases in well-patient checkups and very good or excellent self-assessed health as well as a decrease in obesity. In contrast, no statistically significant improvements are observed for those without a college degree aside from increases in health insurance and having a primary care doctor. In short, both groups experience large gains in insurance coverage but obtaining coverage appears to only lead to substantial new investments in health for highly educated individuals. This is consistent with the prediction of Grossman (1972) that education enables individuals to become more efficient producers of health. It could also reflect underlying differences in time preferences and demand for health. Regardless of the reason, these results are important: while the ACA dependent coverage expansion does lead to many favorable outcomes, these improvements are concentrated among high socioeconomic status (SES) groups. The mandate therefore appears to increase SES-based disparities in health.

In unreported regressions, we conducted the same set of placebo tests as Table 5 for each subsample (results available upon request). We then ran the additional robustness checks with narrower age bandwidths for any outcome in any subsample with multiple placebo test failures. The results from these robustness checks are reported in Appendix Tables A2 and A3. In most cases, the results are not consequentially different from those in Tables 8 and 9.

\section{Effects on Younger Young Adults}

Our preceding analyses focused only on the effects of the ACA dependent coverage mandate on 23-25 year olds. In this section, we provide a preliminary attempt to evaluate the effects on 19-22 year olds. As discussed previously, we expect the impacts on 19-22 year olds to 
be weaker than those on 23-25 year olds, as these younger young adults were more likely to be eligible for their parents' insurance prior to the ACA.

Through trial and error, we found that using 19-22 year olds as the treatment group and 18 plus 27 year olds as the control group leads to placebo tests with approximately the appropriate number of failures (results available upon request). Using these classifications, we re-estimate the baseline specification from equation (1) and report the results in Table 10, alongside the earlier results for 23-25 year olds for comparison purposes. The estimated effect of the ACA provision on insurance coverage is smaller for 19-22 year olds than for 23-25 year olds, and we no longer observe increases in the probabilities of having a primary care doctor and excellent self-assessed health. However, the impact on care foregone because of cost remains about the same, the reduction in body mass index is larger for 19-22 year olds and becomes statistically significant, and we now observe a significant reduction in pregnancies - perhaps due to easier access to birth control or abortions. On the other hand, the reduction in flu vaccinations is even larger for 19-22 year olds, and we observe an additional negative effect on preventive care utilization: a statistically significant reduction in well-patient checkups.

Four of the outcomes - health insurance, pap test in past year, body mass index, and obese - had multiple placebo test failures for this younger sample. We therefore ran additional robustness checks with narrower age bandwidths for these outcomes. The first robustness check uses only 19-20 year olds as the treatment group and only 18 year olds as the control group, while the second compares only 18 and 19 year olds. The results are reported in Appendix Table A4. The most noteworthy difference is that the reduction in BMI is no longer significant in the two robustness checks. In sum, we view the gains from the ACA dependent coverage mandate to be generally weaker for 19-22 year olds than 23-25 year olds: the insurance expansion is smaller 
and the gains in primary care doctor and excellent health disappear. The finding that pregnancies dropped among unmarried 19-22 year old women but not 23-25 year olds, however, stands as a noteworthy exception.

\section{Discussion}

The first major insurance expansion under the ACA - a provision requiring insurers to allow young adults to remain on their parents' health insurance until turning 26 - was implemented in September 2010. This paper uses data from the BRFSS to examine the effects of this mandate on various outcomes related to health care access, preventive care utilization, risky health behaviors, and self-assessed health. We implement a difference-in-differences model with individuals slightly below the mandate’s age cutoff (ages 23-25) as the treatment group and those slightly above the cutoff (ages 27-29) as the control group. We first estimate average effects for the entire sample. The results suggest that the ACA dependent coverage provision increased health care access but not utilization of preventive care, had no clear effects on risky health behaviors, and improved health but only at the high end of the distribution. Specifically, the mandate increased the probabilities of having health insurance, a primary care doctor, and excellent self-assessed health, decreased the probabilities of having medical care foregone because of cost and a flu vaccination, and did not clearly impact the other outcomes. We then validate our model through a series of placebo tests and also show that our classifications of treatment and control groups perform better in these tests that the wider age bandwidths common in the literature. Next, we conduct subsample analyses by pre-ACA state dependent coverage mandate status, sex, race, and education. We find particularly striking improvements in outcomes for college graduates. In addition to stronger effects on health care access and self-assessed excellent health than those for the full sample, college graduates also experienced improvements 
in well-patient checkups, obesity, and very good/excellent health. Finally, we provide a preliminary attempt to estimate the mandate's impacts on 19-22 year olds, finding that they were generally weaker than the effects on 23-25 year olds, with the exception of the emergence of a reduction in pregnancies for unmarried women.

The ACA dependent coverage mandate provides a unique opportunity to study a health insurance intervention specific to young adults as opposed to seniors (Medicare), the poor (Medicaid), or the uninsured population at large (the Massachusetts reform). In general, our results suggest that health insurance affects health-related outcomes of young adults more modestly than prior studies have observed for these other populations. First, we find no evidence of increased preventive care utilization for the full sample, in contrast to prior results from both Medicaid (Finkelstein et al., 2012) and the Massachusetts reform (Kolstad and Kowalski, 2012). Second, we only find evidence of an improvement in overall self-assessed health at the top of the distribution (excellent health), and we do not observe any gains in self-assessed physical or mental health or functional limitations. Clearer effects on all these outcomes have been observed for both Medicaid (Finkelstein et al., 2012) and the Massachusetts reform (Van der Wees et al., 2013; Courtemanche and Zapata, 2014). Our null result for mental health is particularly interesting since health insurance can improve mental health without even affecting health care utilization, simply by reducing stress about financial uncertainty (Finkelstein et al., 2012). Perhaps this stress reduction is relatively small for young adults.

Alternatively, a more optimistic interpretation of our results is that we do observe some improvements in important outcomes, particularly care foregone because of cost and excellent self-assessed health, with gains in additional outcomes also being evident for college graduates. 
One might have initially worried that a coverage expansion for young adults would not lead to any health improvements given the generally good baseline health of this age group.

One important contribution of our paper is that we provide among the most thorough empirical investigations of ex ante moral hazard available in the literature. Prior studies on ex ante moral hazard are rare, and those that exist focus on risky behaviors (e.g. Dave and Kaestner, 2009; Courtemanche and Zapata, 2014). We study not only several risky behaviors, but also investments in preventive care. Indeed, the only clear evidence we find consistent with ex ante moral hazard is for one of the preventive care outcomes: flu vaccinations. A natural question is why ex ante moral hazard might be more relevant for flu vaccinations than physicals or risky behaviors such as smoking, drinking, and having a sedentary lifestyle. One possible explanation is that the downside risks of not having a flu shot - medical expenses associated with the flu occur in the same year. In contrast, expenditures to treat diseases associated with smoking, excessive drinking, obesity, and not having a physical typically occur years down the road. Perhaps uninsured young adults assume that they will be insured by time these downside risks are realized, in which case ex ante moral hazard would not apply.

Another interesting result is that, since the improvement in health is concentrated among college graduates, the ACA dependent coverage provision appears to increase SES-based disparities in health. This is contrary to the usual impacts of public policies to expand health insurance. Medicaid has been shown to improve at least some health outcomes (Currie and Gruber 1996a and 1996b; Finkelstein et al., 2012; Sommers et al., 2012), implying that the program reduces income-based disparities in health. The Massachusetts reform also appears to have reduced income-based disparities, as Courtemanche and Zapata (2014) found the largest gains in self-assessed health among low-income individuals. 
Several caveats to our analyses provide directions for future research. First, we focus on estimating the ACA dependent coverage provision's effects on 23-25 year olds, providing only a brief attempt to also evaluate 19-22 year olds because of the greater difficulty in finding a suitable control group and the weaker ex ante expectations of significant effects. Further understanding whether benefits accrue to young adults besides 23-25 year olds is obviously important in order to fully evaluate the policy. Next, further research is necessary to understand the mechanisms through which the mandate improves health. Our results - the reduction in care foregone because of cost, the lack of effects on preventive care or health behaviors, and the improvement in excellent overall health but not the other self-assessed health variables - are all consistent with increased access to health care leading to better treatment for mild chronic conditions (e.g. allergies, acid reflux, minor depression), but our data do not allow a direct test of this hypothesis. Finally, and critically, our results should not be interpreted as providing a full accounting of the benefits of expanding insurance coverage among young adults. The primary purpose of insurance is to protect individuals from financial risk, and gains along this dimension may be especially substantial for young adults given their relatively low income and wealth levels. Moreover, expanding coverage among young adults is an important component of the overall strategy behind the ACA since it is necessary to offset the additional costs of insuring older and sicker individuals under community rating. In other words, the costs and benefits of the different components of the ACA need to be evaluated together, as the different pieces of the reform are designed to work synergistically. 


\section{References}

Acemoglu, D., Finkelstein, A., and Notowidigdo, M. J. (2013). "Income and Health Spending: Evidence from Oil Price Shocks.” Review of Economics and Statistics, 95(4), 1079-1095.

Anderson, M., Dobkin, C., and Gross, T. (2012). “The Effect of Health Insurance Coverage on the Use of Medical Services.” American Economic Journal: Economic Policy 4(1), 1-27.

Anderson, M., Dobkin, C., and Gross, T. (2014). “The Effect of Health Insurance on Emergency Department Visits: Evidence from an Age-Based Eligibility Threshold.” Review of Economics and Statistics 96(1), 189-195.

Angrist, J. D. and Pischke, J. S. (2008). Mostly Harmless Econometrics: An Empiricist's Companion. Princeton, NJ: Princeton University Press.

Akosa Antwi, Y., Asako, S. M., and Kosali, S. (2013). Effects of Federal Policy to Insure Young Adults: Evidence from the 2010 Affordable Care Act Dependent Coverage Mandate. American Economic Journal: Economic Policy, 5, 1-28.

Akosa Antwi, Y.,Asako, S. M., andKosali, S. (2014). Access to Health Insurance and the Use of Inpatient Medical Care: Evidence from the Affordable Care Act Young Adult Mandate. Indiana University Working Paper.

Apouey, B. and Clark, A. E. (2014). Winning Big but Feeling No Better? The Effect of Lottery Prizes on Physical and Mental Health. Health Economics, forthcoming.

Baicker, K., Taubman S. L., Allen, H. L., Bernstein, M., Gruber, J. H., Newhouse, J. P., Schneider, E. C., Wright, B. J., Zaslavsky, A. M., and Finkelstein, A. N. (2013). The Oregon Experiment - Effects of Medicaid on Clinical Outcomes. New England Journal of Medicine, 368, 1713-1722.

Brook, R. H., Ware, J. E., Rogers, W. H., Keeler, E. B., Davies, A., Donald, C., Goldberg, G. A., Lohr, K., Masthay, P. C., and Newhouse, J. P. (1983). Does Free Care Improve Adults’ Health? Results From a Randomized Controlled Trial. New England Journal of Medicine, 309(23), 1426-1434.

Cantor, J. C., Monheit, A. C., DeLia, D., and Lloyd, K. (2012). Early Impact of the Affordable Care Act on Health Insurance Coverage of Young Adults. Health Services Research, 47(5): 1773-1790.

Card, D., Dobkin, C., and Maestas, N. (2008). The Impact of Nearly Universal Insurance Coverage on Health Care Utilization: Evidence from Medicare. American Economic Review, 98(5), 2242-2258.

Cawley, J. (2004). The Impact of Obesity on Wages. Journal of Human Resources, 39(2), 451474. 
Cawley, J., Moran, J., and Simon, K. (2010). “The Impact of Income on the Weight of Elderly Americans.” Health Economics, 19, 979-993.

Courtemanche, C. and Zapata, D. (2014). Does Universal Coverage Improve Health? The Massachusetts Experience. Journal of Policy Analysis and Management, 33, 36-69.

Courtemanche, C., Heutel, G., and McAlvanah, P. (forthcoming). “Impatience, Incentives, and Obesity.” Economic Journal.

Courtemanche, C., Pinkston, J., and Stewart, J. (2014). “Adjusting Body Mass for Measurement Error with Invalid Validation Data.” National Bureau of Economic Research Working Paper \#19928.

Currie, J. and Gruber J. (1996a). Health Insurance Eligibility, Utilization of Medical Care, and Child Health. Quarterly Journal of Economics, 111(2), 431-466.

Currie, J. and Gruber, J. (1996b). Saving Babies: The Efficacy and Cost of Recent Changes in the Medicaid Eligibility of Pregnant Women. Journal of Political Economy, 104(6), 1263-1296.

Dave, D. and Kaestner, R. (2009). Health Insurance and Ex Ante Moral Hazard: Evidence from Medicare. International Journal of Health Care Finance and Economics, 9(4), 367-390.

Dafny, L. and Gruber, J. (2005). Public Insurance and Child Hospitalizations: Access and Efficiency Effects. Journal of Public Economics, 89, 109-129.

DeNavas-Walt, C., Proctor, B. D., and Smith, J. C. (2010). Income, Poverty, and Health Insurance Coverage in the United States: 2009. U.S. Census Bureau. Washington, D.C.: U.S. Government Printing Office, 1-79.

DeSalvo, K. B., Bloser, N., Reynolds, K., He, J., and Muntner, P. (2006). Mortality prediction with a single general self-rated health question. A meta-analysis. Journal of General Internal Medicine, 21, 267-275.

Ehrlick, I. and Becker, G. S. (1972). Market Insurance, Self-Insurance, and Self-Protection. Journal of Political Economy, 80, 623-648.

Finkelstein, A.N, and McKnight R. (2008). What Did Medicare Do? The Initial Impact of Medicare on Mortality and Out of Pocket Medical Spending. Journal of Public Economics, 92, 1644-1668.

Finkelstein, A. N., Taubman, S., Wright, B., Bernstein, M., Gruber, J., Newhouse, J. P., Allen, H., Baicker, K., and The Oregon Health Study Group. (2012). The Oregon Health 
Insurance Experiment: Evidence from the First Year. Quarterly Journal of Economics, forthcoming.

Frijters, P., Haisken-DeNew, J. P., and Shields, M. (2005). The Causal Effect of Income on Health: Evidence from German Reunification. Journal of Health Economics, 24(5), 9971017.

Grossman, M. (1972). On the Concept of Health Capital and Demand for Health. The Journal of Political Economy, 80, 223-255.

Gruber, J. (2011). The Impacts of the Affordable Care Act: How Reasonable Are the Projections?. National Bureau of Economic Research Working Paper \#17168.

Idler, E. L. and Benyamini, Y. (1997). Self-Rated Health and Mortality: a Review of TwentySeven Community Studies. Journal of Health and Social Behavior, 38, 21-37.

Kolstad, J.T. and Kowalski, A.E. (2012). The Impact of Health Care Reform on Hospital and Preventive Care: Evidence from Massachusetts. Journal of Public Economics, 96, 909929.

Lakdawalla, D. and Philipson, T. (2002). The Growth of Obesity and Technological Change: A Theoretical and Empirical Investigation. National Bureau of Economic Research Working Paper \# 8946.

Levine, P. B., McKnight R., and Heep S. (2011). How Effective are Public Policies to Increase Health Insurance Coverage among Young Adults? American Economic Journal: Economic Policy, 3 (1): 129-156.

Lichtenberg, F.R. (2002). The Effects of Medicare on Health Care Utilization and Outcomes. In Frontiers in Health Policy Research, Volume 5, Cambridge, MA: MIT Press.

Lindahl, M. (2005). "Estimating the Effect of Income on Health and Mortality Using Lottery Prizes as an Exogenous Source of Variation in Income.” Journal of Human Resources, 40(1), 144-168.

Manning, W. G., Newhouse, J. P., Duan, N., Keeler, E. B., Leibowitz, A., and Marquis, M.S. (1987). Health Insurance and the Demand for Medical Care: Evidence from a Randomized Experiment. American Economic Review, 77(3), 251-277.

Miller, S. (2011). The Effect of Insurance on Outpatient Emergency Room Visits: An Analysis of the 2006 Massachusetts Health Reform. Journal of Public Economics, 96, 893-908.

Miller, S. (2012). The Impact of the Massachusetts Health Care Reform on Health Care Use among Children. American Economic Review: Papers and Proceedings, 102(3),502-507. 
Monheit, A., Cantor, J., DeLia, D. and Belloff, D. (2011). How Have State Policies to Expand Dependent Coverage Affected the Health Insurance Status of Young Adults? Health Services Research, 46, 251-267.

National Conference of State Legislatures. (2010). "Covering Young Adults through their Parents' or Guardians' Health Policy." Retrieved from http://www.ncsl.org/research/health/dependent-health-coverage-stateimplementation.aspx

Phillips A. C., Der, G., and Carroll, D. (2010). Self-Reported Health, Self-Reported Fitness, and all-Cause Mortality: Prospective Cohort Study. British Journal of Health Psychology, 15, 337-346.

Ruhm, C. J. (2000). Are Recessions Good For Your Health?. Quarterly Journal of Economics, 115(2), 617-650.

Ruhm, C. J. (2002). Does Drinking Really Decrease in Bad Times?. Journal of Health Economics, 21(4), 659-678.

Ruhm, C. J. (2005). Healthy Living In Hard Times. Journal of Health Economics, 24(2), 341363.

Ruhm, C. J. (2013). Recessions, Healthy No More?. National Bureau of Economic Research Working Paper \#19287.

Schmeiser, M. D. (2009). "Expanding Wallets and Waistlines: The Impact of Family Income on the BMI of Women and Men Eligible for the Earned Income Tax Credit." Health Economics, 18, 1277-1294.

Slusky, D. J. G. (2013). Revisiting the Labor Effects of the Affordable Care Act. Princeton University Working Paper.

Snyder, S. E. and Evans, W. N. (2006). "The Impact of Income on Mortality: Evidence from the Social Security Notch.” Review of Economics and Statistics, 88(3), 482-495.

Sommers, B. D., Baicker, K., and Epstein, A. M. (2012). Mortality and Access to Care among Adults after State Medicaid Expansions. New England Journal of Medicine, 367, 10251034.

Sommers, B. D., Buchmueller, T., Decker, S. L., Carey, C. and Kronick, R. (2013). The Affordable Care Act Has Led to Significant Gains in Health Insurance and Access to Care for Young Adults. Health Affairs, 32, 165-174.

Sommers, B. D., and Kronick, R. (2012). The Affordable Care Act and Insurance Coverage for Young Adults. Journal of the American Medical Association, 307 (9): 913-4. 
Sommers, B. D., Long, S.K., and Baicker, K. (2014). Changes in Mortality After Massachusetts Health Care Reform: A Quasi-Experimental Study. Annals of Internal Medicine, 160(9), 585-593.

Taubman, S.L., Allen, H.L., Wright, B.J., Baicker, K., and Finkelstein, A.N. (2014). Medicaid Increases Emergency-Department Use: Evidence from Oregon's Health Insurance Experiment. Science, 343, 263-268.

Tekin, E., McClellan, C., and Minyard, K.J. (2013). Health and Health Behaviors during the Worst of Times: Evidence from the Great Recession. National Bureau of Economic Research Working Paper \#19234.

Van der Wees, P.J., Zaslavsky, A.M., and Ayanian, J.Z. (2013). Improvements in Health Status after Massachusetts Health Care Reform. Milbank Quarterly, 91, 663-689. 
Figure 1 -- Trends in Access to Care and Preventive Care Variables by Age Group
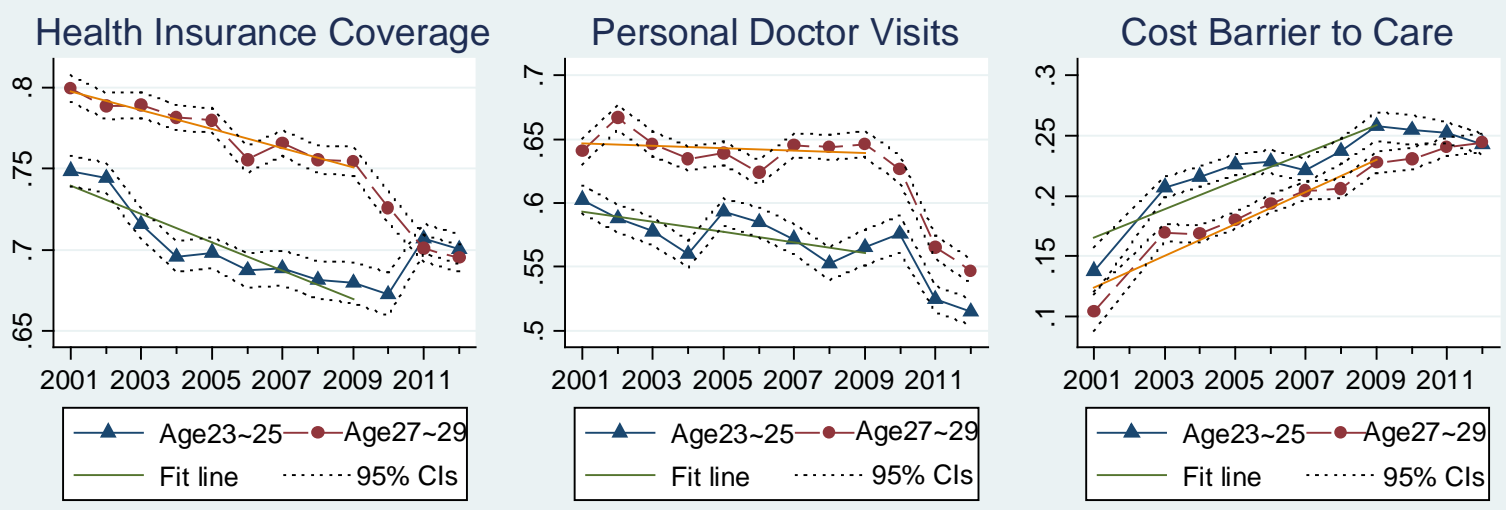

Flu Shots
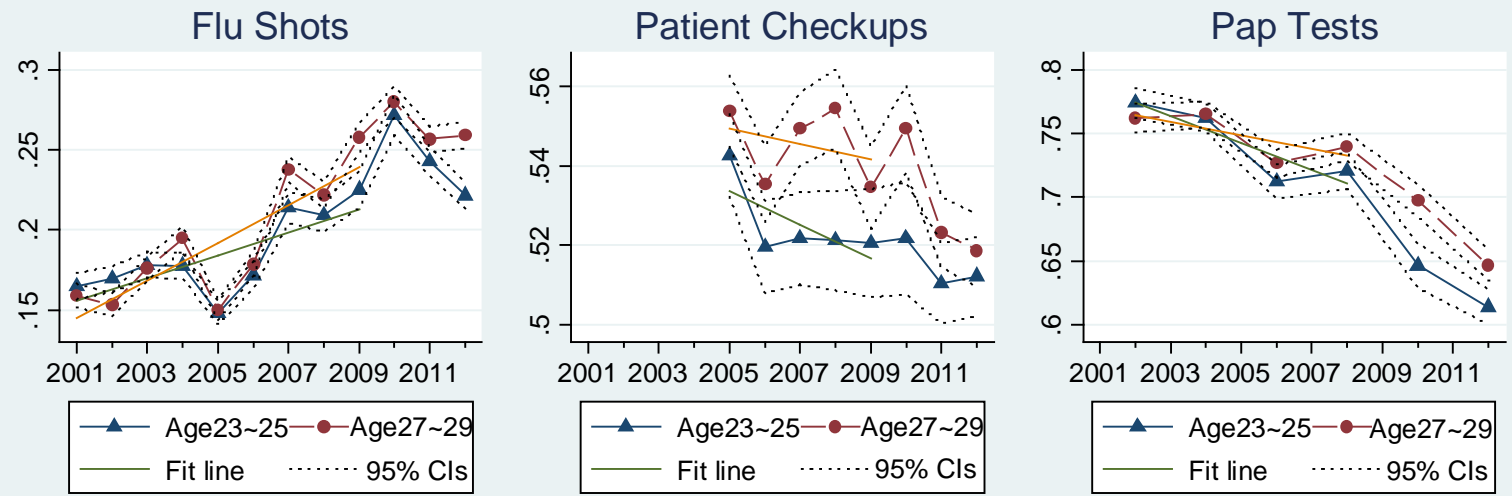
Figure 2 -- Trends in Health Behavior Variables by Age Group
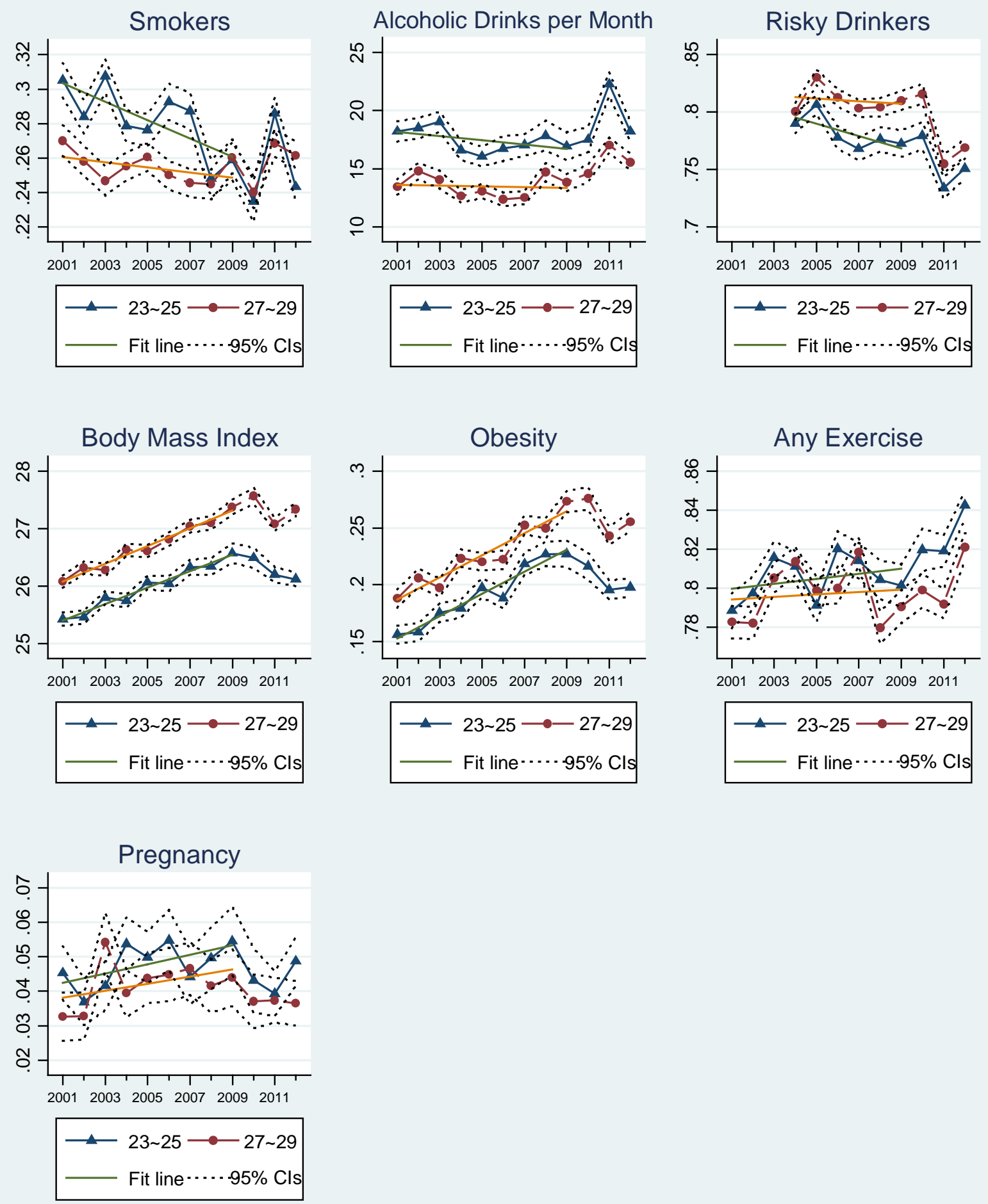


\section{Figure 3 -- Trends in Self-Assessed Health Variables by Age Group}

Overall Health - Very Good \& Excellent
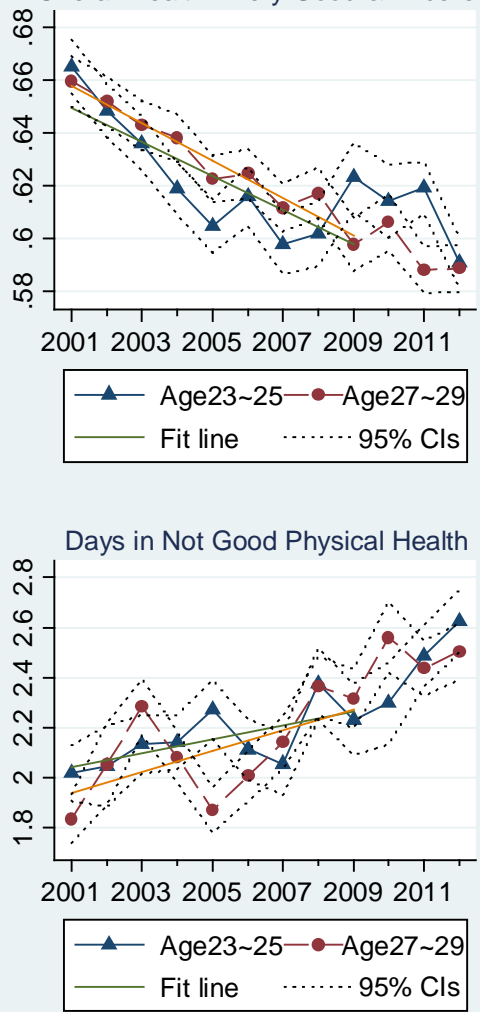

Overall Health - Excellent

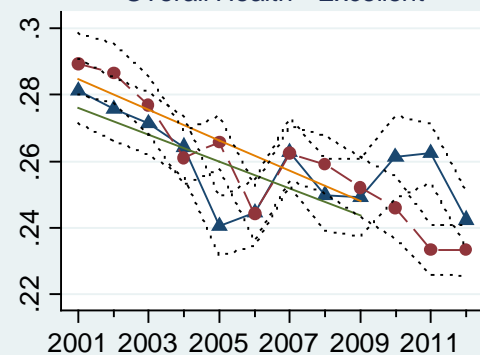

200120032005200720092011

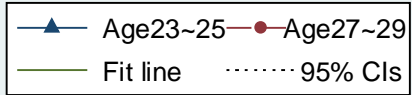

Days in Functional Limitation

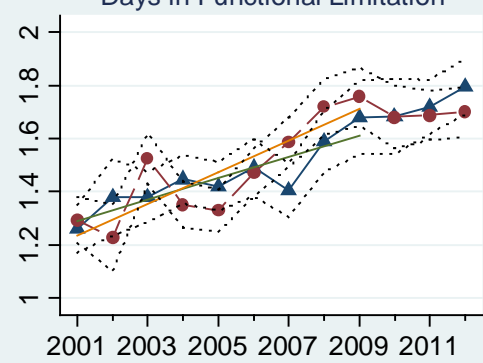

$\simeq$ Age23 25-•Age27 29

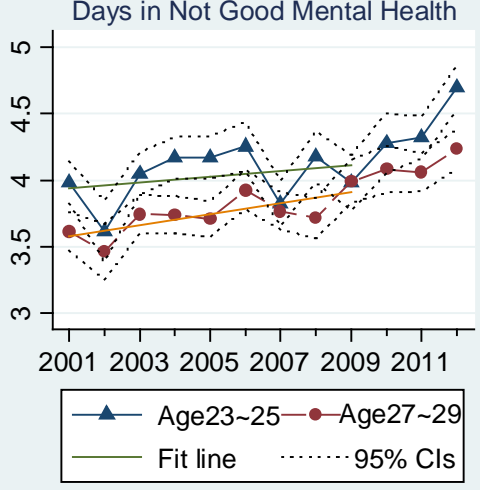

$95 \% \mathrm{Cls}$ 
Table 1 - Sample Sizes for Different Outcomes

\begin{tabular}{lccc}
\hline \hline Outcome Variable & Total & $\begin{array}{c}\text { Treatment } \\
(23-25)\end{array}$ & $\begin{array}{c}\text { Control } \\
(27-29)\end{array}$ \\
\hline Health care access & & & \\
$\quad$ Any health insurance coverage & 85,597 & 35,294 & 50,303 \\
$\quad$ Any primary care doctor & 80,003 & 32,943 & 47,060 \\
$\quad$ Cost prevented care in past year & 66,684 & 27,251 & 39,433 \\
Preventive care utilization & & & \\
$\quad$ Flu vaccination in past year & 64,873 & 26,422 & 38,451 \\
Well-patient checkup in past year & 66,739 & 27,276 & 39,463 \\
$\quad$ Pap test in past year (women only) & $26,919^{+}$ & 10,799 & 16,120 \\
Risky health behaviors & & & \\
Currently smokes cigarettes & 85,147 & 35,120 & 50,027 \\
$\quad$ Alcoholic drinks in past 30 days & 81,325 & 33,436 & 47,889 \\
$\quad$ Risky drinker in past 30 days & 80,682 & 33,144 & 47,538 \\
Body mass index & 81,284 & 33,632 & 47,652 \\
Obese & 81,284 & 33,632 & 47,652 \\
Any exercise in past 30 days & 83,511 & 34,461 & 49,050 \\
$\quad$ Pregnancy (unmarried women only) & 26,832 & 13,133 & 13,699 \\
Self-assessed health & & & \\
Overall health very good or excellent & 85,541 & 35,321 & 50,220 \\
Overall health excellent & 85,541 & 35,321 & 50,220 \\
Days of last 30 not in good mental health & 83,937 & 34,708 & 49,229 \\
Days of last 30 not in good physical health & 83,988 & 34,707 & 49,281 \\
Days of last 30 with health-related limitations & 84,329 & 34,867 & 49,462 \\
\hline
\end{tabular}

${ }^{+}$The pap test variable is only available in even-numbered years, reducing the sample size for that outcome. 
Table 2 - Pre-Treatment Means and Standard Deviations for Control Variables

\begin{tabular}{|c|c|c|}
\hline Control Variable & Treatment (Ages 23-25) & Control (Ages 27-29) \\
\hline \multicolumn{3}{|l|}{ Age dummies (age $=23$ is omitted) } \\
\hline Age $=24$ & $0.349(0.477)$ & \\
\hline Age $=25$ & $0.321(0.467)$ & \\
\hline Age $=27$ & & $0.308(0.461)$ \\
\hline Age $=28$ & & $0.341(0.474)$ \\
\hline Age $=29$ & & $0.352(0.477)$ \\
\hline Female & $0.504(0.500)$ & $0.505(0.500)$ \\
\hline \multicolumn{3}{|c|}{ Race/ethnicity dummies (non-Hispanic white is omitted) } \\
\hline Non-Hispanic black & $0.114(0.318)$ & $0.119(0.323)$ \\
\hline Hispanic & $0.222(0.415)$ & $0.213(0.410)$ \\
\hline Other than black, Hispanic, or white & $0.093(0.290)$ & $0.076(0.266)$ \\
\hline Currently married & $0.292(0.455)$ & $0.556(0.497)$ \\
\hline \multicolumn{3}{|c|}{ Education dummies (less than high school degree is omitted) } \\
\hline High school degree but no further & $0.283(0.450)$ & $0.253(0.435)$ \\
\hline Some college but no four-year degree & $0.297(0.457)$ & $0.277(0.448)$ \\
\hline College graduate & $0.307(0.461)$ & $0.358(0.479)$ \\
\hline \multicolumn{3}{|c|}{ Household income dummies (less than $\$ 10,000$ is omitted) } \\
\hline Between $\$ 10,000$ and $\$ 15,000$ & $0.069(0.253)$ & $0.052(0.223)$ \\
\hline Between $\$ 15,000$ and $\$ 20,000$ & $0.102(0.303)$ & $0.081(0.273)$ \\
\hline Between $\$ 20,000$ and $\$ 25,000$ & $0.116(0.320)$ & $0.098(0.297)$ \\
\hline Between $\$ 25,000$ and $\$ 35,000$ & $0.139(0.346)$ & $0.126(0.332)$ \\
\hline Between $\$ 35,000$ and $\$ 50,000$ & $0.163(0.369)$ & $0.160(0.367)$ \\
\hline Between $\$ 50,000$ and $\$ 75,000$ & $0.140(0.347)$ & $0.185(0.388)$ \\
\hline$\$ 75,000$ and over & $0.186(0.389)$ & $0.236(0.425)$ \\
\hline \multicolumn{3}{|c|}{ Number of children in household dummies ( 0 is omitted) } \\
\hline One child & $0.228(0.420)$ & $0.233(0.423)$ \\
\hline Two children & $0.158(0.365)$ & $0.234(0.424)$ \\
\hline Three children & $0.057(0.232)$ & $0.109(0.312)$ \\
\hline Four children & $0.017(0.130)$ & $0.036(0.187)$ \\
\hline Five or more children & $0.008(0.090)$ & $0.016(0.126)$ \\
\hline Cell phone only & $0.645(0.479)^{+}$ & $0.604(0.489)^{+}$ \\
\hline Student & $0.113(0.317)$ & $0.055(0.227)$ \\
\hline Unemployed & $0.128(0.334)$ & $0.108(0.310)$ \\
\hline State unemployment rate & $7.922(2.492)$ & $8.134(2.470)$ \\
\hline Pre-ACA state mandate & $0.271(0.444)$ & $0.045(0.207)$ \\
\hline
\end{tabular}

Notes: BRFSS sampling weights are used. Means are reported, with standard deviations in parentheses. ${ }^{+}$indicates the summary statistics are from 2011-2012, since the variable is 0 for all respondents in all prior years. 
Table 3 - Means and Standard Deviations for Outcome Variables

\begin{tabular}{|c|c|c|c|c|c|}
\hline \multirow[b]{2}{*}{ Outcome Variable } & \multicolumn{2}{|c|}{ Pre-Treatment Period } & \multicolumn{2}{|c|}{ 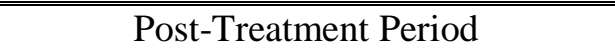 } & \multirow{2}{*}{$\begin{array}{l}\text { Difference-in- } \\
\text { Difference }\end{array}$} \\
\hline & $\begin{array}{c}\text { Treatment (Ages } \\
\text { 23-25) }\end{array}$ & $\begin{array}{c}\text { Control (Ages 27- } \\
\text { 29) }\end{array}$ & $\begin{array}{c}\text { Treatment (Ages } \\
\text { 23-25) }\end{array}$ & $\begin{array}{c}\text { Control (Ages 27- } \\
\text { 29) }\end{array}$ & \\
\hline \multicolumn{6}{|l|}{ Health care access } \\
\hline Any health insurance coverage & $0.677(0.468)$ & $0.748(0.434)$ & $0.703(0.457)$ & $0.700(0.458)$ & $0.074(0.013)^{* * *}$ \\
\hline Any primary care doctor & $0.561(0.496)$ & $0.639(0.480)$ & $0.526(0.499)$ & $0.564(0.496)$ & $0.039(0.013)^{* * *}$ \\
\hline Cost prevented care in past year & $0.248(0.432)$ & $0.220(0.414)$ & $0.249(0.432)$ & $0.242(0.428)$ & $-0.020(0.011)^{*}$ \\
\hline \multicolumn{6}{|l|}{ Preventive care utilization } \\
\hline Flu vaccination in past year & $0.229(0.420)$ & $0.249(0.432)$ & $0.235(0.424)$ & $0.261(0.439)$ & $-0.007(0.012)$ \\
\hline Well-patient checkup in past year & $0.520(0.500)$ & $0.543(0.498)$ & $0.513(0.500)$ & $0.527(0.499)$ & $0.009(0.014)$ \\
\hline Pap test in past year & $0.693(0.461)$ & $0.724(0.447)$ & $0.623(0.485)$ & $0.656(0.475)$ & $-0.002(0.021)$ \\
\hline \multicolumn{6}{|l|}{ Risky health behaviors } \\
\hline Currently smokes cigarettes & $0.250(0.433)$ & $0.250(0.433)$ & $0.261(0.439)$ & $0.262(0.440)$ & $-0.001(0.011)$ \\
\hline Alcoholic drinks in past 30 days & $17.478(45.580)$ & $14.394(36.540)$ & $19.937(44.679)$ & $16.065(36.643)$ & $0.788(1.301)$ \\
\hline Risky drinker in past 30 days & $0.777(0.416)$ & $0.809(0.393)$ & $0.744(0.436)$ & $0.769(0.422)$ & $0.007(0.012)$ \\
\hline Body mass index & $26.433(5.889)$ & $27.331(6.072)$ & $26.215(6.131)$ & 27.235 (6.198) & $-0.122(0.166)$ \\
\hline Obese & $0.223(0.416)$ & $0.265(0.441)$ & $0.200(0.400)$ & $0.252(0.434)$ & $-0.010(0.011)$ \\
\hline Any exercise in past 30 days & $0.808(0.394)$ & $0.792(0.406)$ & $0.829(0.377)$ & $0.802(0.398)$ & $0.009(0.012)$ \\
\hline Pregnancy & $0.050(0.218)$ & $0.042(0.200)$ & $0.044(0.205)$ & $0.037(0.188)$ & $-0.001(0.009)$ \\
\hline \multicolumn{6}{|l|}{ Self-assessed health } \\
\hline Overall health very good/excellent & $0.611(0.488)$ & $0.610(0.488)$ & $0.607(0.488)$ & $0.587(0.492)$ & $0.018(0.012)$ \\
\hline Overall health excellent & $0.252(0.434)$ & $0.255(0.436)$ & $0.254(0.435)$ & $0.233(0.422)$ & $0.025(0.010)^{* *}$ \\
\hline Days not in good mental health & $4.135(7.741)$ & $3.872(7.742)$ & $4.486(8.117)$ & $4.185(8.082)$ & $0.038(0.201)$ \\
\hline Days not in good physical health & $2.309(5.583)$ & $2.362(5.904)$ & $2.534(6.133)$ & $2.520(6.229)$ & $0.067(0.161)$ \\
\hline Days with health-related limitation & $1.658(4.906)$ & $1.693(5.243)$ & $1.736(5.131)$ & $1.730(5.309)$ & $0.040(0.138)$ \\
\hline
\end{tabular}

Notes: Standard errors, heteroskedasticity-robust and clustered at the age-by-time level, are in parentheses. BRFSS sampling weights are used. Means are reported, with standard deviations in parentheses. *** indicates the difference-in-difference is significant at the $1 \%$ level; ** $5 \%$; * $10 \%$. 
Table 4 - Difference-in-Differences Estimates of Effects of ACA Dependent Coverage Mandate on Health-Related Outcomes

\begin{tabular}{|c|c|c|c|c|c|}
\hline Outcome Variable & Baseline Model & $\begin{array}{l}\text { Demographic } \\
\text { Controls Only }\end{array}$ & Start in 2005 & Start in 2001 & Drop 3/10-12/10 \\
\hline \multicolumn{6}{|l|}{ Health care access } \\
\hline Any health insurance & $0.062(0.010) * * *[0.132]$ & $0.065(0.011)^{* * *}$ & $0.058(0.008)^{* * *}$ & $0.056(0.008)^{* * *}$ & $0.067(0.011)^{* * *}$ \\
\hline Any primary doctor & $0.036(0.010)^{* * *}[0.064]$ & $0.037(0.010)^{* * *}$ & $0.018(0.009)^{* *}$ & $0.022(0.008) * * *$ & $0.039(0.011)^{* * *}$ \\
\hline Cost prevented care & $-0.025(0.011)^{* *}[-0.058]$ & $-0.023(0.011)^{* *}$ & $-0.022(0.010)^{* *}$ & $-0.025(0.010) * * *$ & $-0.028(0.012)^{* *}$ \\
\hline \multicolumn{6}{|l|}{ Preventive care utilization } \\
\hline Flu vaccination & $-0.026(0.011)^{* *}[-0.062]$ & $-0.025(0.011)^{* *}$ & $-0.027(0.009) * * *$ & $-0.027(0.009) * * *$ & $-0.021(0.013)^{*}$ \\
\hline Well-patient checkup & 0.008 (0.014) [0.016] & $0.008(0.014)$ & $0.006(0.012)$ & $0.006(0.012)$ & $0.014(0.016)$ \\
\hline Pap test & $-0.004(0.018)[-0.009]$ & $-0.003(0.019)$ & $-0.012(0.017)$ & $-0.025(0.015)^{*}$ & $-0.015(0.020)$ \\
\hline \multicolumn{6}{|l|}{ Risky health behaviors } \\
\hline Currently smokes & $0.010(0.009)[0.023]$ & $0.004(0.009)$ & $-0.004(0.008)$ & $-0.010(0.007)$ & $0.007(0.010)$ \\
\hline Drinks per month & $1.674(1.045)[0.037]$ & $1.146(1.084)$ & $0.960(0.849)$ & $0.614(0.781)$ & 1.799 (1.163) \\
\hline Risky drinker & $0.008(0.010)[0.019]$ & $0.007(0.010)$ & $0.010(0.008)$ & $0.007(0.008)$ & $0.011(0.011)$ \\
\hline Body mass index & $-0.075(0.142)[-0.013]$ & $-0.130(0.139)$ & $-0.139(0.122)$ & $-0.160(0.112)$ & $-0.180(0.152)$ \\
\hline Obese & $-0.006(0.010)[-0.014]$ & $-0.010(0.010)$ & $-0.009(0.008)$ & $-0.008(0.008)$ & $-0.012(0.011)$ \\
\hline Any exercise & 0.002 (0.009) [0.005] & $0.006(0.009)$ & 0.007 (0.007) & $0.009(0.007)$ & $-0.001(0.009)$ \\
\hline Pregnancy & $-0.003(0.008)[-0.014]$ & $-0.002(0.008)$ & $-0.0002(0.006)$ & $0.0003(0.006)$ & $-0.004(0.009)$ \\
\hline \multicolumn{6}{|l|}{ Self-assessed health } \\
\hline Very good/exc. Health & $0.012(0.010)[0.025]$ & $0.013(0.011)$ & $0.014(0.009)^{*}$ & $0.015(0.008)^{*}$ & $0.007(0.011)$ \\
\hline Excellent health & $0.022(0.010)^{* *}[0.051]$ & $0.021(0.009)^{* *}$ & $0.022(0.008)^{* * *}$ & $0.021(0.007)^{* * *}$ & $0.024(0.010)^{* *}$ \\
\hline Days not good mental & $0.084(0.181)[0.011]$ & $0.077(0.180)$ & $0.112(0.156)$ & $0.091(0.148)$ & $0.193(0.194)$ \\
\hline Days not good phys. & $0.120(0.145)[0.021]$ & $0.119(0.144)$ & $0.029(0.125)$ & $0.051(0.119)$ & $0.150(0.149)$ \\
\hline Days health limitations & $0.105(0.131)[0.021]$ & $0.101(0.129)$ & $0.102(0.115)$ & $0.081(0.110)$ & $0.214(0.141)$ \\
\hline
\end{tabular}

Notes: *** indicates significant at the 1\% level; ** 5\%; * 10\%. Standard errors, heteroskedasticity-robust and clustered at the age-by-time level, are in parentheses. All regressions include the controls plus state and time fixed effects. BRFSS sampling weights are used. For the baseline regression, effect sizes in standard deviations of the dependent variable (for the treatment group in the pre-treatment period) are in brackets. 
Table 5 - Placebo Regressions

\begin{tabular}{|c|c|c|c|c|c|c|}
\hline Outcome Variable & $\begin{array}{c}\text { 2005-2009 } \\
\text { Treatment 10/07 }\end{array}$ & $\begin{array}{c}\text { 2004-2008 } \\
\text { Treatment 10/06 }\end{array}$ & $\begin{array}{c}\text { 2003-2007 } \\
\text { Treatment 10/05 }\end{array}$ & $\begin{array}{c}\text { 2002-2006 } \\
\text { Treatment 10/04 }\end{array}$ & $\begin{array}{c}\text { 2001-2005 } \\
\text { Treatment 10/03 }\end{array}$ & $\begin{array}{l}\text { Treated: 27-29 } \\
\text { Control: 31-33 }\end{array}$ \\
\hline \multicolumn{7}{|l|}{ Health care access } \\
\hline Insurance & $-0.008(0.012)$ & $-0.003(0.011)$ & $0.015(0.010)$ & $-0.006(0.010)$ & $-0.016(0.009)^{*}$ & $0.010(0.008)$ \\
\hline Doctor & $-0.030(0.012)^{* *}$ & $-0.007(0.012)$ & $0.010(0.011)$ & $0.034(0.010)^{* * *}$ & $0.003(0.010)$ & $-0.003(0.009)$ \\
\hline Cost prevent & $0.005(0.011)$ & $-0.002(0.012)$ & $-0.019(0.011)^{*}$ & $-0.010(0.011)$ & $0.003(0.013)$ & $0.004(0.009)$ \\
\hline \multicolumn{7}{|c|}{ Preventive care utilization } \\
\hline Flu vaccin. & $-0.010(0.015)$ & $-0.003(0.012)$ & $-0.016(0.011)$ & $-0.002(0.010)$ & $-0.009(0.009)$ & $0.021(0.009)^{* *}$ \\
\hline Checkup & $0.004(0.016)$ & $-0.004(0.016)$ & $-0.001(0.018)$ & -- & -- & $0.006(0.012)$ \\
\hline Pap test & $0.031(0.037)$ & $-0.012(0.020)$ & $-0.012(0.035)$ & $-0.027(0.018)$ & $-0.030(0.026)$ & $-0.018(0.017)$ \\
\hline \multicolumn{7}{|c|}{ Risky health behaviors } \\
\hline Smoker & $-0.031(0.010) * * *$ & $-0.003(0.010)$ & $0.002(0.010)$ & $-0.011(0.010)$ & $-0.016(0.009)^{*}$ & $-0.025(0.008) * * *$ \\
\hline Drinks/month & $-0.903(1.226)$ & -1.358 (1.139) & $-0.620(1.000)$ & $-1.276(0.988)$ & $-0.519(0.883)$ & $-0.990(0.802)$ \\
\hline Risky drinker & $0.002(0.011)$ & $0.001(0.010)$ & $-0.017(0.010)$ & $-0.009(0.013)$ & -- & $-0.003(0.008)$ \\
\hline BMI & $0.009(0.146)$ & $0.085(0.137)$ & $-0.098(0.135)$ & $-0.075(0.127)$ & $-0.051(0.113)$ & $0.131(0.127)$ \\
\hline Obese & $0.002(0.011)$ & $0.009(0.010)$ & $-0.004(0.010)$ & $0.001(0.009)$ & $-0.001(0.008)$ & $0.003(0.009)$ \\
\hline Any exercise & $0.009(0.010)$ & $0.008(0.009)$ & $0.006(0.009)$ & $-0.002(0.010)$ & $-0.012(0.009)$ & $-0.009(0.007)$ \\
\hline Pregnancy & $0.003(0.009)$ & $0.004(0.009)$ & $0.008(0.010)$ & $0.003(0.009)$ & $0.002(0.009)$ & $0.003(0.007)$ \\
\hline \multicolumn{7}{|l|}{ Self-assessed health } \\
\hline V.good/exc. & $0.004(0.012)$ & $-0.003(0.011)$ & $0.008(0.011)$ & $0.006(0.010)$ & $-0.012(0.010)$ & $0.012(0.009)$ \\
\hline Excellent & $0.002(0.011)$ & $0.001(0.010)$ & $0.011(0.009)$ & $0.002(0.009)$ & $0.008(0.009)$ & $-0.013(0.008)$ \\
\hline Days mental & $-0.001(0.189)$ & $0.040(0.181)$ & $-0.126(0.172)$ & $0.059(0.170)$ & $0.127(0.165)$ & $-0.060(0.151)$ \\
\hline Days phys. & $-0.161(0.131)$ & $-0.044(0.126)$ & $0.027(0.123)$ & $0.356(0.129)^{* * *}$ & $0.125(0.129)$ & $-0.084(0.131)$ \\
\hline Days limit. & $-0.070(0.117)$ & $-0.067(0.110)$ & $0.004(0.105)$ & $0.089(0.104)$ & $0.048(0.101)$ & $-0.239(0.110)^{* *}$ \\
\hline
\end{tabular}

Notes: ${ }^{* *}$ indicates significant at the $1 \%$ level; ** 5\%; * $10 \%$. Standard errors, heteroskedasticity-robust and clustered at the age-by-time level, are in parentheses. All regressions include the controls plus state and time fixed effects. BRFSS sampling weights are used. 
Table 6 - Additional Robustness Checks for Outcomes with Multiple Placebo Test Failures

\begin{tabular}{lccc}
\hline \hline \multirow{2}{*}{ Outcome Variable } & $\begin{array}{c}\text { Estimates from Table 4 Column 1 } \\
\text { Treatment Group: Ages 23-25 } \\
\text { Control Group: Ages 27-29 }\end{array}$ & $\begin{array}{c}\text { New Estimates } \\
\text { Treatment Group: Ages 24-25 } \\
\text { Control Group: Ages 27-28 }\end{array}$ & $\begin{array}{c}\text { New Estimates } \\
\text { Treatment Group: Age 25 } \\
\text { Control Group: Age 27 }\end{array}$ \\
\hline Any primary care doctor & $0.036(0.010)^{* * *}$ & $0.028(0.011)^{* *}$ & $0.033(0.013)^{* * *}$ \\
Currently smokes cigarettes & $0.010(0.009)$ & $0.016(0.011)$ & $0.002(0.012)$ \\
\hline
\end{tabular}

See notes for Table 5.

Table 7 - Summary of Placebo Test Results with Different Age Ranges

\begin{tabular}{|c|c|c|c|c|c|c|}
\hline Treatment Group & Control Group & $\begin{array}{c}\text { \% Significant at } \\
\text { 1\% Level }\end{array}$ & $\begin{array}{c}\text { \% Significant at } \\
\text { 5\% Level or } \\
\text { Better }\end{array}$ & $\begin{array}{c}\text { \% Significant at } \\
\text { 10\% Level or } \\
\text { Better }\end{array}$ & $\begin{array}{c}\text { Number of } \\
\text { Outcomes with } \\
\text { No Significant } \\
\text { Results }\end{array}$ & $\begin{array}{c}\text { Number of } \\
\text { Outcomes with } 0 \\
\text { or } 1 \text { Significant } \\
\text { Results }\end{array}$ \\
\hline Ages 23-25 & Ages 27-29 & $3.8 \%$ & $6.7 \%$ & $9.5 \%$ & 11 & 16 \\
\hline Ages 22-25 & Ages 27-30 & $2.9 \%$ & $8.6 \%$ & $11.4 \%$ & 11 & 14 \\
\hline Ages 21-25 & Ages 27-31 & $3.8 \%$ & $11.4 \%$ & $20.0 \%$ & 7 & 14 \\
\hline Ages 20-25 & Ages 27-32 & $4.8 \%$ & $14.3 \%$ & $23.8 \%$ & 7 & 12 \\
\hline Ages 19-25 & Ages 27-33 & $4.8 \%$ & $15.2 \%$ & $24.8 \%$ & 6 & 12 \\
\hline Ages 19-25 & Ages 18, 27-29 & $1.9 \%$ & $4.8 \%$ & $13.3 \%$ & 7 & 15 \\
\hline
\end{tabular}

See notes for Table 5 . Bold denotes the baseline model from Table 4 . 
Table 8 - Heterogeneity by Prior State Dependent Coverage Mandate and Sex

\begin{tabular}{|c|c|c|c|c|}
\hline \multirow[b]{2}{*}{ Outcome Variable } & \multicolumn{2}{|c|}{ Prior State Mandate } & \multicolumn{2}{|c|}{ Sex } \\
\hline & No Prior Mandate & Prior Mandate & Female & Male \\
\hline \multicolumn{5}{|l|}{ Health care access } \\
\hline Any health insurance coverage & $0.089(0.018)^{* * *}$ & $0.051(0.012)^{* * *}$ & $0.048(0.012)^{* * *}$ & $0.073(0.015)^{* * *}$ \\
\hline Any primary care doctor & $0.022(0.018)$ & $0.041(0.013)^{* * *}$ & $0.012(0.013)$ & $0.058(0.017)^{* * *}$ \\
\hline Cost prevented care in past year & $-0.016(0.019)$ & $-0.031(0.014)^{* *}$ & $-0.016(0.014)$ & $-0.030(0.016)^{*}$ \\
\hline \multicolumn{5}{|l|}{ Preventive care utilization } \\
\hline Flu vaccination in past year & $-0.020(0.017)$ & $-0.028(0.013)^{* *}$ & $-0.043(0.015) * * *$ & $-0.015(0.017)$ \\
\hline Well-patient checkup in past year & $0.034(0.024)$ & $-0.002(0.016)$ & $0.004(0.016)$ & $0.009(0.021)$ \\
\hline Pap test in past year & $0.008(0.032)$ & $-0.008(0.022)$ & $-0.004(0.018)$ & -- \\
\hline \multicolumn{5}{|l|}{ Risky health behaviors } \\
\hline Currently smokes cigarettes & $0.013(0.015)$ & $0.011(0.012)$ & $0.017(0.010)^{*}$ & $0.006(0.014)$ \\
\hline Alcoholic drinks in past 30 days & $1.891(1.618)$ & $1.801(1.276)$ & $0.560(0.590)$ & $2.710(1.876)$ \\
\hline Risky drinker & $0.012(0.016)$ & $0.004(0.012)$ & $0.006(0.011)$ & $0.013(0.016)$ \\
\hline Body mass index & $-0.324(0.255)$ & $0.036(0.160)$ & $-0.129(0.197)$ & $0.031(0.182)$ \\
\hline Obese & $-0.015(0.017)$ & $-0.002(0.011)$ & $-0.013(0.012)$ & $0.002(0.015)$ \\
\hline Any exercise in past 30 days & $0.015(0.016)$ & $-0.004(0.011)$ & $-0.009(0.012)$ & $0.016(0.013)$ \\
\hline Pregnancy & $0.007(0.013)$ & $-0.006(0.010)$ & $-0.003(0.008)$ & -- \\
\hline \multicolumn{5}{|l|}{ Self-assessed health } \\
\hline Overall health very good or excellent & $0.023(0.019)$ & $0.005(0.013)$ & $-0.002(0.014)$ & $0.027(0.016)^{*}$ \\
\hline Overall health excellent & $0.034(0.018)^{*}$ & $0.018(0.012)$ & $0.002(0.012)$ & $0.044(0.015)^{* * *}$ \\
\hline Days of last 30 not in good mental health & $0.333(0.315)$ & $-0.036(0.213)$ & $0.063(0.234)$ & $0.105(0.260)$ \\
\hline Days of last 30 not in good physical health & $-0.172(0.284)$ & $0.245(0.155)$ & $0.148(0.188)$ & $0.068(0.208)$ \\
\hline Days of last 30 with health-related limitations & $0.016(0.251)$ & $0.124(0.138)$ & $0.294(0.173)^{*}$ & $-0.089(0.188)$ \\
\hline
\end{tabular}


Table 9 - Heterogeneity by Race and Education

\begin{tabular}{|c|c|c|c|c|}
\hline \multirow[b]{2}{*}{ Outcome Variable } & \multicolumn{2}{|c|}{ Race } & \multicolumn{2}{|c|}{ Education } \\
\hline & White & Non-White & Not College Graduate & College Graduate \\
\hline \multicolumn{5}{|l|}{ Health care access } \\
\hline Any health insurance coverage & $0.063(0.011)^{* * *}$ & $0.060(0.018)^{* * *}$ & $0.074(0.013)^{* * *}$ & $0.052(0.013) * * *$ \\
\hline Any primary care doctor & $0.026(0.012)^{* *}$ & $0.048(0.019)^{* *}$ & $0.023(0.013)^{*}$ & $0.073(0.018)^{* * *}$ \\
\hline Cost prevented care in past year & $-0.042(0.011)^{* * *}$ & $-0.003(0.020)$ & $-0.022(0.014)$ & $-0.035(0.013)^{* * *}$ \\
\hline \multicolumn{5}{|l|}{ Preventive care utilization } \\
\hline Flu vaccination in past year & $-0.018(0.013)$ & $-0.038(0.019)^{* *}$ & $-0.027(0.014)^{* *}$ & $-0.023(0.018)$ \\
\hline Well-patient checkup in past year & $0.007(0.015)$ & $0.014(0.022)$ & $-0.002(0.017)$ & $0.043(0.020)^{* *}$ \\
\hline Pap test in past year & $-0.008(0.021)$ & $-0.003(0.031)$ & $-0.007(0.023)$ & $0.008(0.027)$ \\
\hline \multicolumn{5}{|l|}{ Risky health behaviors } \\
\hline Currently smokes cigarettes & $0.012(0.012)$ & $0.008(0.015)$ & $0.011(0.013)$ & $0.004(0.011)$ \\
\hline Alcoholic drinks in past 30 days & $2.062(1.117)^{*}$ & $1.083(1.779)$ & $1.978(1.444)$ & $0.971(1.028)$ \\
\hline Risky drinker in past 30 days & $0.009(0.012)$ & $0.010(0.016)$ & $0.010(0.012)$ & $-0.001(0.015)$ \\
\hline Body mass index & $0.004(0.175)$ & $-0.159(0.247)$ & $0.071(0.180)$ & $-0.309(0.190)$ \\
\hline Obese & $-0.007(0.011)$ & $-0.004(0.018)$ & $0.007(0.013)$ & $-0.028(0.014)^{* *}$ \\
\hline Any exercise in past 30 days & $-0.009(0.009)$ & $0.017(0.016)$ & $-0.003(0.011)$ & $0.014(0.013)$ \\
\hline Pregnancy & $-0.009(0.008)$ & $0.007(0.013)$ & $-0.005(0.011)$ & $-0.001(0.008)$ \\
\hline \multicolumn{5}{|l|}{ Self-assessed health } \\
\hline Overall health very good or excellent & $0.013(0.011)$ & $0.009(0.020)$ & $-0.002(0.013)$ & $0.037(0.016)^{* *}$ \\
\hline Overall health excellent & $0.032(0.011)^{* * *}$ & $0.007(0.017)$ & $0.007(0.011)$ & $0.053(0.017)^{* * *}$ \\
\hline Days of last 30 not in good mental health & $0.080(0.214)$ & $0.061(0.313)$ & $0.190(0.240)$ & $-0.179(0.206)$ \\
\hline Days of last 30 not in good physical health & $-0.048(0.167)$ & $0.353(0.215)$ & $0.300(0.192)$ & $-0.245(0.165)$ \\
\hline Days of last 30 with health-related limitations & $0.254(0.133)^{*}$ & $-0.107(0.231)$ & $0.257(0.171)$ & $-0.169(0.144)$ \\
\hline
\end{tabular}


Table 10 - Effects on Younger Young Adults

\begin{tabular}{|c|c|c|}
\hline Outcome Variable & $\begin{array}{c}\text { Estimates from Table } 4 \text { Column } 1 \\
\text { Treatment Group: Ages 23-25 } \\
\text { Control Group: Ages 27-29 }\end{array}$ & $\begin{array}{c}\text { Estimates for Younger Young Adults } \\
\text { Treatment Group: Ages 19-22 } \\
\text { Control Group: Ages } 18 \text { and } 27\end{array}$ \\
\hline \multicolumn{3}{|l|}{ Health care access } \\
\hline Any health insurance coverage & $0.062(0.010)^{* * *}$ & $0.045(0.012)^{* * *}$ \\
\hline Any primary care doctor & $0.036(0.010)^{* * *}$ & $0.002(0.013)$ \\
\hline Cost prevented care in past year & $-0.025(0.011)^{* *}$ & $-0.025(0.011)^{* *}$ \\
\hline \multicolumn{3}{|l|}{ Preventive care utilization } \\
\hline Flu vaccination in past year & $-0.026(0.011)^{* *}$ & $-0.033(0.014)^{* *}$ \\
\hline Well-patient checkup in past year & $0.008(0.014)$ & $-0.032(0.016)^{* *}$ \\
\hline Pap test in past year & $-0.004(0.018)$ & $-0.026(0.021)$ \\
\hline \multicolumn{3}{|l|}{ Risky health behaviors } \\
\hline Currently smokes cigarettes & $0.010(0.009)$ & $-0.008(0.011)$ \\
\hline Alcoholic drinks in past 30 days & $1.674(1.045)$ & $1.320(1.070)$ \\
\hline Risky drinker in past 30 days & $0.008(0.010)$ & $0.001(0.010)$ \\
\hline Body mass index & $-0.075(0.142)$ & $-0.284(0.145)^{*}$ \\
\hline Obese & $-0.006(0.010)$ & $-0.005(0.011)$ \\
\hline Any exercise in past 30 days & $0.002(0.009)$ & $0.007(0.010)$ \\
\hline Pregnancy & $-0.003(0.008)$ & $-0.016(0.008)^{* *}$ \\
\hline \multicolumn{3}{|l|}{ Self-assessed health } \\
\hline Overall health very good or excellent & $0.012(0.010)$ & $-0.006(0.013)$ \\
\hline Overall health excellent & $0.022(0.010)^{* *}$ & $0.002(0.012)$ \\
\hline Days of last 30 not in good mental health & $0.084(0.181)$ & $0.148(0.209)$ \\
\hline Days of last 30 not in good physical health & $0.120(0.145)$ & $0.113(0.134)$ \\
\hline Days of last 30 with health-related limitations & $0.105(0.131)$ & $0.135(0.126)$ \\
\hline
\end{tabular}

See notes for Table 5. 


\section{Appendix}

Table A1 - Full Regression Output for Selected Dependent Variables

\begin{tabular}{|c|c|c|c|}
\hline Control Variable & Insurance & Smoker & Excellent Health \\
\hline Treated*Post & $0.062(0.010)^{* * *}$ & $0.010(0.009)$ & $0.022(0.010)^{* *}$ \\
\hline Age $=24$ & $-0.006(0.010)$ & $-0.002(0.009)$ & $0.007(0.009)$ \\
\hline Age $=25$ & $-0.013(0.010)$ & $0.019(0.008)^{* *}$ & $0.006(0.009)$ \\
\hline Age $=27$ & $0.006(0.011)$ & $0.033(0.010)^{* * *}$ & $-0.012(0.010)$ \\
\hline Age $=28$ & $0.015(0.011)$ & $0.050(0.010)^{* * *}$ & $-0.018(0.011)$ \\
\hline Age $=29$ & $0.026(0.012)^{* *}$ & $0.040(0.009)^{* * *}$ & $-0.010(0.010)$ \\
\hline Female & $0.063(0.005)^{* * *}$ & $-0.055(0.005) * * *$ & $-0.023(0.006)^{* * *}$ \\
\hline Non-Hispanic black & $-0.015(0.010)$ & $-0.128(0.009)^{* * *}$ & $0.008(0.010)$ \\
\hline Hispanic & $-0.123(0.009) * * *$ & $-0.186(0.008)^{* * *}$ & $-0.008(0.008)$ \\
\hline Other than black, Hispanic, or white & $-0.010(0.011)$ & $-0.027(0.010)^{* *}$ & $-0.004(0.012)$ \\
\hline Currently married & $0.069(0.006)^{* * *}$ & $-0.110(0.006)^{* * *}$ & $0.021(0.006)^{* * *}$ \\
\hline High school degree but no further & $0.105(0.012)^{* * *}$ & $-0.086(0.011)^{* * *}$ & $0.038(0.010) * * *$ \\
\hline Some college but no 4-year degree & $0.166(0.012)^{* * *}$ & $-0.160(0.011)^{* * *}$ & $0.052(0.010)^{* * *}$ \\
\hline College graduate & $0.247(0.013) * * *$ & $-0.311(0.012)^{* * *}$ & $0.113(0.010)^{* * *}$ \\
\hline Between $\$ 10,000$ and $\$ 15,000$ & $-0.047(0.017) * * *$ & $-0.004(0.015)$ & $-0.005(0.014)$ \\
\hline Between $\$ 15,000$ and $\$ 20,000$ & $-0.080(0.014)^{* * *}$ & $0.022(0.014)$ & $0.003(0.012)$ \\
\hline Between $\$ 20,000$ and $\$ 25,000$ & $-0.039(0.013) * * *$ & $0.0005(0.013)$ & $0.004(0.011)$ \\
\hline Between $\$ 25,000$ and $\$ 35,000$ & $0.040(0.014)^{* * *}$ & $-0.017(0.014)$ & $0.032(0.012) * * *$ \\
\hline Between $\$ 35,000$ and $\$ 50,000$ & $0.109(0.013)^{* * *}$ & $-0.035(0.013) * * *$ & $0.045(0.011)^{* * *}$ \\
\hline Between $\$ 50,000$ and $\$ 75,000$ & $0.160(0.013)^{* * *}$ & $-0.066(0.013) * * *$ & $0.059(0.011)^{* * *}$ \\
\hline$\$ 75,000$ and over & $0.172(0.014)^{* * *}$ & $-0.055(0.013) * * *$ & $0.117(0.013)^{* * *}$ \\
\hline One child in household & $0.030(0.007)^{* * *}$ & $0.038(0.007)^{* * *}$ & $-0.012(0.007)$ \\
\hline Two children in household & $0.041(0.008)^{* * *}$ & $0.045(0.008)^{* * *}$ & $-0.004(0.008)$ \\
\hline Three children in household & $0.029(0.012)^{* *}$ & $0.061(0.012)^{* * *}$ & $-0.017(0.010)^{*}$ \\
\hline Four children in household & $0.016(0.018)$ & $0.065(0.019)^{* * *}$ & $-0.047(0.014)^{* * *}$ \\
\hline Five or more children in household & $0.048(0.028) *$ & $0.051(0.025)^{* *}$ & $-0.028(0.023)$ \\
\hline Cell phone only & $-0.007(0.008)$ & $0.008(0.008)$ & $0.007(0.008)$ \\
\hline Student & $-0.007(0.010)$ & $-0.026(0.009)^{* * *}$ & $0.014(0.010)$ \\
\hline Unemployed & $-0.171(0.010)^{* * *}$ & $0.105(0.010)^{* * *}$ & $-0.034(0.008)^{* * *}$ \\
\hline State unemployment rate & $0.003(0.005)$ & $-0.008(0.004)^{* *}$ & $0.001(0.004)$ \\
\hline Pre-ACA state mandate & $0.015(0.010)$ & $0.002(0.009)$ & $-0.022(0.009)^{* *}$ \\
\hline
\end{tabular}

Notes: *** indicates significant at the 1\% level; ** 5\%; * 10\%. Standard errors, heteroskedasticity-robust and clustered at the age-by-time level, are in parentheses. All regressions also include the state and time fixed effects. BRFSS sampling weights are used. Separate variables for "treated” and "post” are not included because they are subsumed by the age and time fixed effects. 
Table A2 - Additional Robustness Checks for Prior Mandate/Sex Subsample Outcomes with Multiple Placebo Test Failures

\begin{tabular}{|c|c|c|c|}
\hline Outcome Variable & $\begin{array}{c}\text { Estimates from Table } 8 \\
\text { Treatment Group: Ages 23-25 } \\
\text { Control Group: Ages 27-29 }\end{array}$ & $\begin{array}{c}\text { New Estimates } \\
\text { Treatment Group: Ages 24-25 } \\
\text { Control Group: Ages 27-28 }\end{array}$ & $\begin{array}{c}\text { New Estimates } \\
\text { Treatment Group: Age } 25 \\
\text { Control Group: Age } 27\end{array}$ \\
\hline \multicolumn{4}{|l|}{ No prior law } \\
\hline Any primary care doctor & $0.022(0.018)$ & $0.028(0.022)$ & $0.017(0.025)$ \\
\hline Days with health-related limitations & $0.016(0.251)$ & $0.034(0.288)$ & $0.214(0.273)$ \\
\hline \multicolumn{4}{|l|}{ Prior } \\
\hline Any primary care doctor & $0.041(0.013)^{* * *}$ & $0.029(0.014)^{* *}$ & $0.041(0.016)^{* *}$ \\
\hline Currently smokes cigarettes & $0.011(0.012)$ & $0.012(0.014)$ & $-0.007(0.017)$ \\
\hline Alcoholic drinks in past 30 days & $1.801(1.276)$ & $0.553(1.626)$ & $-0.832(2.086)$ \\
\hline Days not in good physical health & $0.245(0.155)$ & $0.276(0.181)$ & $0.183(0.199)$ \\
\hline \multicolumn{4}{|l|}{ Female } \\
\hline Flu vaccination in past year & $-0.043(0.015) * * *$ & $-0.037(0.018) * *$ & $-0.071(0.016) * * *$ \\
\hline Currently smokes cigarettes & $0.017(0.010)^{*}$ & $0.014(0.011)$ & $0.029(0.013)^{* *}$ \\
\hline Alcoholic drinks in past 30 days & $0.560(0.590)$ & $0.518(0.688)$ & $1.397(0.808)^{*}$ \\
\hline Days not in good physical health & $0.148(0.188)$ & $0.298(0.219)$ & $0.508(0.210)^{* *}$ \\
\hline Days with health-related limitations & $0.294(0.173)^{*}$ & $0.317(0.206)$ & $0.608(0.201)^{* * *}$ \\
\hline \multicolumn{4}{|l|}{ Male } \\
\hline Any primary care doctor & $0.058(0.017)^{* * *}$ & $0.049(0.018)^{* * *}$ & $0.063(0.017)^{* * *}$ \\
\hline Currently smokes cigarettes & $0.006(0.014)$ & $0.020(0.017)$ & $-0.019(0.019)$ \\
\hline
\end{tabular}

See notes for Table 5. 
Table A3 - Additional Robustness Checks for Race/Education Subsample Outcomes with Multiple Placebo Test Failures

\begin{tabular}{|c|c|c|c|}
\hline Outcome Variable & $\begin{array}{c}\text { Estimates from Table } 9 \\
\text { Treatment Group: Ages 23-25 } \\
\text { Control Group: Ages 27-29 }\end{array}$ & $\begin{array}{c}\text { New Estimates } \\
\text { Treatment Group: Ages 24-25 } \\
\text { Control Group: Ages 27-28 }\end{array}$ & $\begin{array}{c}\text { New Estimates } \\
\text { Treatment Group: Age } 25 \\
\text { Control Group: Age } 27\end{array}$ \\
\hline \multicolumn{4}{|c|}{ (2) } \\
\hline Any health insurance coverage & $0.063(0.011)^{* * *}$ & $0.042(0.013)^{* * *}$ & $0.046(0.015)^{* * *}$ \\
\hline Flu vaccination in past year & $-0.018(0.013)$ & $-0.032(0.013)^{* *}$ & $-0.051(0.014)^{* * *}$ \\
\hline Currently smokes cigarettes & $0.012(0.012)$ & $0.009(0.013)$ & $-0.013(0.014)$ \\
\hline Overall health very good/excellent & $0.013(0.011)$ & $0.001(0.013)$ & $-0.008(0.016)$ \\
\hline Days with health-related limitations & $0.254(0.133)^{*}$ & $0.379(0.148)^{* *}$ & $0.448(0.151)^{* * *}$ \\
\hline \multicolumn{4}{|l|}{ Non-white } \\
\hline Any primary care doctor & $0.048(0.019) * *$ & $0.028(0.021)$ & $0.008(0.022)$ \\
\hline Cost prevented care in past year & $-0.003(0.020)$ & $0.023(0.022)$ & $0.053(0.025) * *$ \\
\hline Days not in good physical health & $0.353(0.215)$ & $0.243(0.233)$ & $0.042(0.268)$ \\
\hline \multicolumn{4}{|l|}{ Not college graduate } \\
\hline Currently smokes cigarettes & $0.011(0.013)$ & $0.020(0.015)$ & $0.003(0.017)$ \\
\hline Overall health excellent & $0.007(0.011)$ & $0.005(0.013)$ & $-0.012(0.014)^{* *}$ \\
\hline \multicolumn{4}{|l|}{ College graduate } \\
\hline Any primary care doctor & $0.073(0.018)^{* * *}$ & $0.079(0.021)^{* * *}$ & $0.074(0.024)^{* * *}$ \\
\hline Flu vaccination in past year & $-0.023(0.018)$ & $-0.023(0.020)$ & $-0.030(0.018)^{*}$ \\
\hline Currently smokes cigarettes & $0.004(0.011)$ & $0.002(0.013)$ & $-0.001(0.015)$ \\
\hline Overall health very good/excellent & $0.037(0.016)^{* *}$ & $0.031(0.018)^{*}$ & $0.020(0.022)$ \\
\hline Overall health excellent & $0.053(0.017) * * *$ & $0.037(0.020)^{*}$ & $0.049(0.021) * *$ \\
\hline Days not in good mental health & $-0.179(0.206)$ & $0.052(0.243)$ & $0.171(0.306)$ \\
\hline
\end{tabular}


Table A4 - Additional Robustness Checks for Younger Young Adults Outcomes with Multiple Placebo Test Failures

\begin{tabular}{lccc}
\hline \hline \multirow{2}{*}{$\begin{array}{l}\text { Eutcome Variable } \\
\text { Any health insurance coverage }\end{array}$} & $\begin{array}{c}\text { New Estimates } \\
\text { Control Group: Ages 18 and 27 }\end{array}$ & $\begin{array}{c}\text { New Estimates } \\
\text { Control Group: Age 18 }\end{array}$ & $\begin{array}{c}\text { Treatment Group: Age 19 } \\
\text { Control Group: Age 18 }\end{array}$ \\
\hline Pap test in past year & $0.045(0.012)^{* * *}$ & $0.037(0.014)^{* *}$ & $0.044(0.015)^{* * *}$ \\
Body mass index & $-0.026(0.021)$ & $0.008(0.028)$ & $0.017(0.028)$ \\
Obese & $-0.284(0.145)^{*}$ & $-0.282(0.203)$ & $-0.096(0.205)$ \\
\end{tabular}

See notes for Table 5 . 